\title{
LRRCE: a leucine-rich repeat cysteine capping motif unique to the chordate lineage
}

\author{
Hosil Park ${ }^{1}$, Julie Huxley-Jones ${ }^{1,3}$, Ray P Boot-Handford ${ }^{1}$, Paul N Bishop ${ }^{1}$, \\ Teresa K Attwood ${ }^{2}$ and Jordi Bella*1
}

\begin{abstract}
Address: ${ }^{1}$ Wellcome Trust Centre for Cell-Matrix Research, Faculty of Life Sciences, University of Manchester, Manchester, M13 9PT, UK, ${ }^{2}$ Faculty of Life Sciences and School of Computer Science, University of Manchester, Manchester, M13 9PT, UK and ${ }^{3}$ Computational Biology, Molecular Discovery Research, GlaxoSmithKline Pharmaceuticals, Harlow, Essex, CM19 5AW, UK

Email: Hosil Park - hosil@yahoo.com; Julie Huxley-Jones - julie.x.huxley-jones@gsk.com; Ray P Boot-Handford - ray.boothandford@manchester.ac.uk; Paul N Bishop - paul.n.bishop@manchester.ac.uk; Teresa K Attwood - teresa.k.attwood@manchester.ac.uk; Jordi Bella* - jordi.bella@manchester.ac.uk

* Corresponding author
\end{abstract}

Published: 12 December 2008

BMC Genomics 2008, 9:599 doi:10.1/86/147|-2164-9-599
Received: 9 July 2008

Accepted: 12 December 2008

This article is available from: http://www.biomedcentral.com/I47I-2/64/9/599

(c) 2008 Park et al; licensee BioMed Central Ltd.

This is an Open Access article distributed under the terms of the Creative Commons Attribution License (http://creativecommons.org/licenses/by/2.0), which permits unrestricted use, distribution, and reproduction in any medium, provided the original work is properly cited.

\begin{abstract}
Background: The small leucine-rich repeat proteins and proteoglycans (SLRPs) form an important family of regulatory molecules that participate in many essential functions. They typically control the correct assembly of collagen fibrils, regulate mineral deposition in bone, and modulate the activity of potent cellular growth factors through many signalling cascades. SLRPs belong to the group of extracellular leucine-rich repeat proteins that are flanked at both ends by disulphidebonded caps that protect the hydrophobic core of the terminal repeats. A capping motif specific to SLRPs has been recently described in the crystal structures of the core proteins of decorin and biglycan. This motif, designated as LRRCE, differs in both sequence and structure from other, more widespread leucine-rich capping motifs. To investigate if the LRRCE motif is a common structural feature found in other leucine-rich repeat proteins, we have defined characteristic sequence patterns and used them in genome-wide searches.
\end{abstract}

Results: The LRRCE motif is a structural element exclusive to the main group of SLRPs. It appears to have evolved during early chordate evolution and is not found in protein sequences from nonchordate genomes. Our search has expanded the family of SLRPs to include new predicted protein sequences, mainly in fishes but with intriguing putative orthologs in mammals. The chromosomal locations of the newly predicted SLRP genes would support the large-scale genome or gene duplications that are thought to have occurred during vertebrate evolution. From this expanded list we describe a new class of SLRP sequences that could be representative of an ancestral SLRP gene.

Conclusion: Given its exclusivity the LRRCE motif is a useful annotation tool for the identification and classification of new SLRP sequences in genome databases. The expanded list of members of the SLRP family offers interesting insights into early vertebrate evolution and suggests an early chordate evolutionary origin for the LRRCE capping motif. 


\section{Background}

The leucine-rich repeat (LRR) is a widespread structural motif of 20-30 amino acids easily identifiable at the primary structure level by the characteristic 11-residue hallmark sequence $\mathrm{L} x x \mathrm{~L} x \mathrm{~L} x x \mathrm{~N} x \mathrm{~L}$, where $x$ means any amino acid and the consensus Leu and Asn positions are often substituted by other hydrophobic residues such as Ile, Val, Phe, Cys, etc [1-5]. Proteins with LRR-architecture typically contain two or more LRRs in tandem and have been identified in all life forms, from viruses to eukaryotes [6]. The continuously expanding LRR superfamily includes intracellular, extracellular and membrane-attached proteins characterized by a common modular architecture specially suited to favour protein-protein interactions [1$3,5,7-9]$. These proteins participate in a variety of important biological functions, including among others cell adhesion and signalling, platelet aggregation, neural development, extracellular matrix assembly, bacterial pathogenicity, disease resistance and immune response [10-20]. LRR-containing proteins and domains form curved solenoid structures where each repeat is a turn of the solenoid. The concave side of the solenoid is defined by a parallel $\beta$-sheet interwoven with a variety of structures in the convex side which include $\alpha$ helices, $3_{10}$ helices, polyproline II helices, tandems of $\beta$ turns and short $\beta$ strands $[1-5,9,21]$. The biological roles of LRR proteins and domains typically relate to their ability to engage in protein-protein interactions. However, some family members recognize other ligand types such as nucleic acids, lipopolysaccharides, lipopeptides, and even small compounds such as auxins [19,22-27]. The sites for ligand recognition map preferentially but not exclusively to the concave sites of the LRR arched structures, as demonstrated by several crystal structures of LRR proteins in complex with their ligands (see [5] for a recent review). Recently, some LRR proteins have been shown to form highly stable dimers through their concave side [28-31] raising the possibility of alternative scenarios where LRR dimers are either the functional units or latent forms that require dissociation prior to ligand binding [32].
A distinct group of LRR proteins from the extracellular matrix forms the family known as small leucine-rich repeat proteins and proteoglycans (SLRPs) [10,32-34]. These molecules are emerging as an important family or regulatory proteins with still undiscovered functions. They typically control the correct assembly of collagen fibrils, regulate mineral deposition in bone, and modulate the activity of potent cellular growth factors through signal transduction [10,33-35]. SLRPs have in common clusters of cysteine residues flanking their LRR domains at both $\mathrm{N}$ - and C-termini. The crystal structures of the two most studied SLRPs, decorin and biglycan, have been recently determined $[29,31]$.

SLRPs have been traditionally classified into three classes (I, II and III) depending on their gene organisation, number of LRRs and spacing of cysteine residues at the amino-terminal cluster $[10,32,33]$. Other LRR molecules have been subsequently added to the family and two additional, non-canonical classes IV and $\mathrm{V}$ have been defined [34]. Class IV and V SLRPs show clear differences with those of the three first classes in number of repeats and internal repeat structure $[32,34,36-39]$; their classification as SLRPs is due to functional similarity with canonical SLRPs, extracellular location, and presence of cysteine clusters flanking the LRR domain.

Many LRR proteins other than SLRPs are flanked at the Nand C-termini by disulphide-bonded caps that are thought to protect the hydrophobic core of the first and last LRRs [2,3]. Both N-terminal and C-terminal capping motifs are described in databases for protein domain identification and analysis such as SMART [40], Pfam [41] and InterPro [42] (Table 1). In the LRR N-terminal capping motif (LRRNT), a single $\beta$-strand runs antiparallel to the main $\beta$-sheet and is followed by a short LRR of 20 or 21 residues (Figure $1 \mathrm{a}$ ). The consensus sequence contains 4 cysteines in a $\mathrm{C} x_{n} \mathrm{C} x \mathrm{C} x_{m} \mathrm{C}$ pattern, with $n$ and $m$ being variable numbers.

Table I: LRR cysteine-capping motifs described in the protein domain databases InterPro (16.2) [42], SMART (5.I) [40] and Pfam (22.0) [4I], with current numbers of matches.

\begin{tabular}{|c|c|c|c|c|}
\hline Name & Description & Database & Accession & Matches \\
\hline \multirow[t]{3}{*}{ LRRNT } & $\mathrm{N}$-terminal capping & SMART & SM00013 & 5596 \\
\hline & & InterPro & IPR000372 & 2610 \\
\hline & & Pfam & PF0I462 & 1572 \\
\hline \multirow{2}{*}{ LRRNP } & $\mathrm{N}$-terminal capping (plant specific) & InterPro & IPROI32I0 & 2517 \\
\hline & & Pfam & PF08263 & 1326 \\
\hline \multirow[t]{3}{*}{ LRRCT } & C-terminal capping & SMART & SM00082 & 4715 \\
\hline & & InterPro & IPR000483 & 1476 \\
\hline & & Pfam & PFOI463 & 399 \\
\hline
\end{tabular}



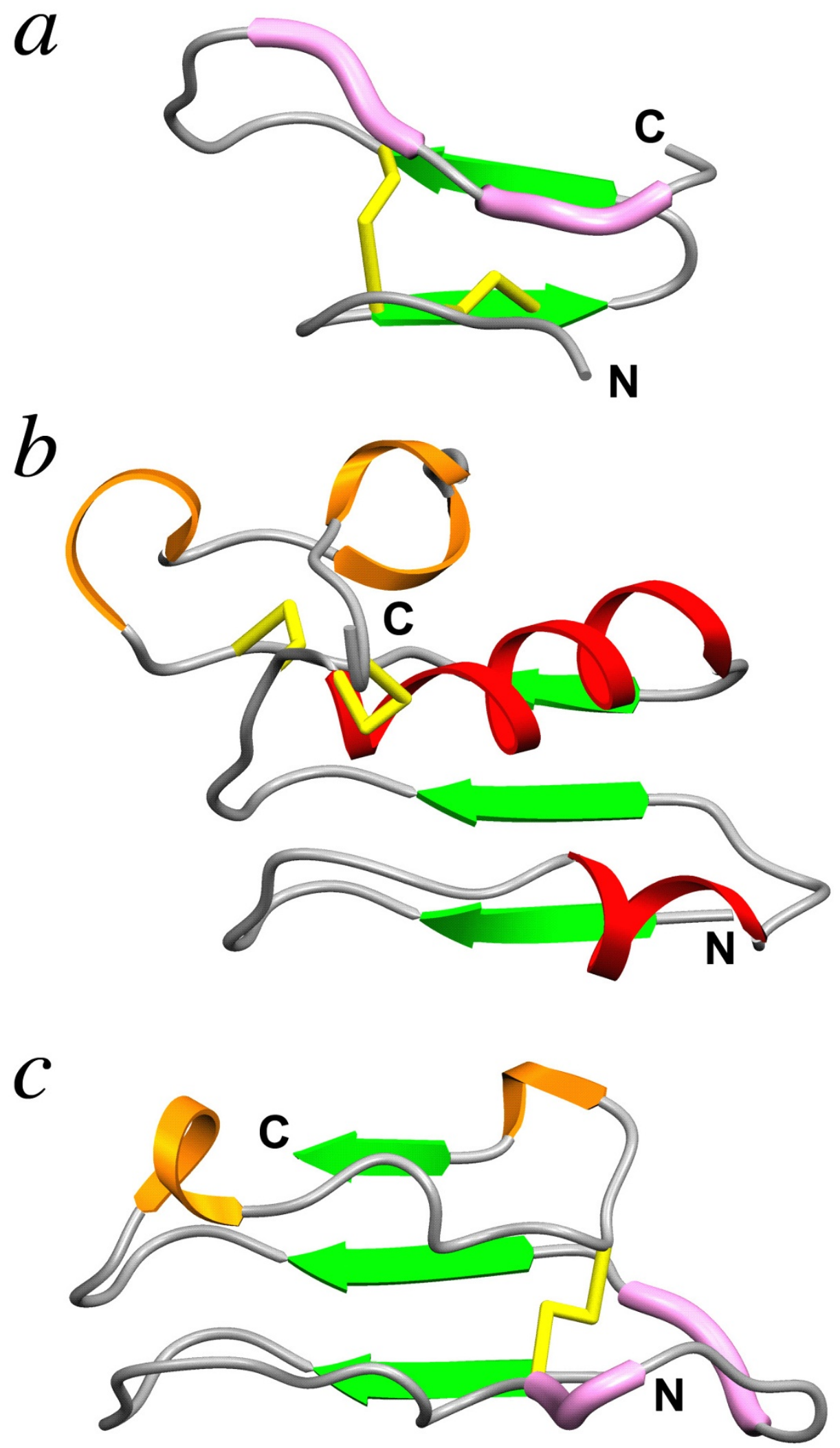

Figure I (see legend on next page) 
Figure I (see previous page)

Ribbon diagrams of different cysteine-capping motifs in LRR structures, viewed from the convex side of the LRR domains: (a) the LRRNT capping motif in the crystal structure of bovine decorin [29], PDB code IXKU; (b) the LRRCT capping motif in the crystal structure of the Nogo receptor ectodomain [46], PDB code 1OZN; (c) the LRRCE capping motif in the crystal structure of bovine decorin [29]. The different secondary structure elements are identified as follows: green arrows, $\beta$-strands; red ribbons, $\alpha$-helices; orange ribbons, $3_{10}$ helices and $\beta$-turns; pink tubes, short polyproline II segments; yellow sticks, disulphide bonds. The $\mathrm{N}$ - and $\mathrm{C}$-terminal ends in each panel are indicated. (Reproduced from [5] with permission from Birkhäuser Verlag AG)

The cysteines form a disulphide knot that connects the antiparallel $\beta$ strand to the first LRR. This motif is characteristic of all proteins from the SLRP family as well as secreted or membrane-bound LRR proteins. Its main structural elements appear to be maintained irrespective of the number and spacing of cysteines [32]. A variation of the LRRNT capping motif specific to plants has also been described (LRRNP, Table 1). Its architecture and disulphide-bonding topology differs from that of LRRNT, as observed in the crystal structure of a polygalacturonase inhibitor from Phaseolus vulgaris [43].

The LRR C-terminal capping motif (LRRCT) contains normally four cysteines that stabilize the local structure with two disulphide bonds [44-47]. Characteristic of this motif is an $\alpha$ helix that covers the hydrophobic core of the last LRR (Figure 1b). This capping motif seems to occur slightly less often than LRRNT (Table 1) and appears to be exclusive to animal proteins. Many cysteine-capped LRR proteins have been automatically annotated as having either N-terminal or C-terminal capping structures, although close inspection of their sequences shows that in many cases both capping motifs are actually present.

In early sequence analyses, Kajava and Kobe classified the disulphide-bonded C-terminal capping motifs in four different subfamilies, named CF1 to CF4 $[2,3]$. Sequences from the CF1 subfamily contain four cysteine residues and are the ones typically detected by current LRRCT database descriptors in automatic sequence annotation (Table 1). The CF2 subfamily is characterized by only two cysteines and was defined for some members of the SLRP family. The CF3 and CF4 subfamilies are specific to G-protein coupled receptors and plants, respectively. Protein sequence databases do not include separate descriptors for these four subfamilies, and sequences from the CF2 subfamily are not recognized by current LRRCT descriptors. The structure of the C-terminal capping motif from the CF2 subfamily was elucidated in the crystal structures of the protein cores of decorin and biglycan [29,31], both being representative members of the SLRP family. This capping motif is structurally quite different from LRRCT [32]. It extends to the last two LRRs, which are connected by a single disulphide bond (Figure 1c). The second-to- last LRR appears to be longer than all the other ones, and in the crystal structures of decorin and biglycan is extended laterally from the main LRR fold [29,31]. We have previously named this longer, extended repeat as the "ear" repeat, and we will use the term LRRCE throughout this paper to designate the ear-containing LRR C-terminal capping motif. All extracellular LRR proteins currently classified as members of the SLRP family have N-terminal capping motifs of the LRRNT type, but their C-terminal motifs show variability. While chondroadherin and nyctalopin C-terminal sequences correspond to that of a typical LRRCT motif, the SLRPs from the canonical group (which here refers to classes I, II and III plus extracellular matrix protein 2, ECM2) show the LRRCE capping motif [29,32]. Podocan, a recent addition to the SLRP family and class $\mathrm{V}$ representative, does not have any C-terminal capping $[32,36]$.

To investigate if the LRRCE motif is a common structural feature in other LRR proteins, we have defined characteristic sequence patterns based on a set of sequences from class I, II and III SLRPs and we have used those patterns in genome-wide searches. We present in this paper the results of this analysis.

\section{Results and discussion \\ A comprehensive list of LRRCE-containing sequences}

The final regular expression pattern for the LRRCE capping motif and its mapping to the three-dimensional structure of bovine decorin are shown in Figure 2. Using the LRRCE regular expression pattern, a total of 175 sequences were retrieved by ScanProsite from the UniProt database (Swiss-Prot release 55.1, TrEMBL release 38.1) [48]. Splice variants were excluded from the search and sequence duplicates were filtered, resulting in a nonredundant set of 110 UniProt sequences. Figure 3 shows a selection of aligned LRRCE sequences from this nonredundant set (an extended list of sequences including accession codes is available in Additional File 1), plus two sequences from urochordates (discussed later). The LRRCE regular expression pattern was accurate: all sequences in this UniProt set were of proteins with LRR architecture and had a repeat structure that identified them as canonical SLRPs, with the LRRNT capping motif 

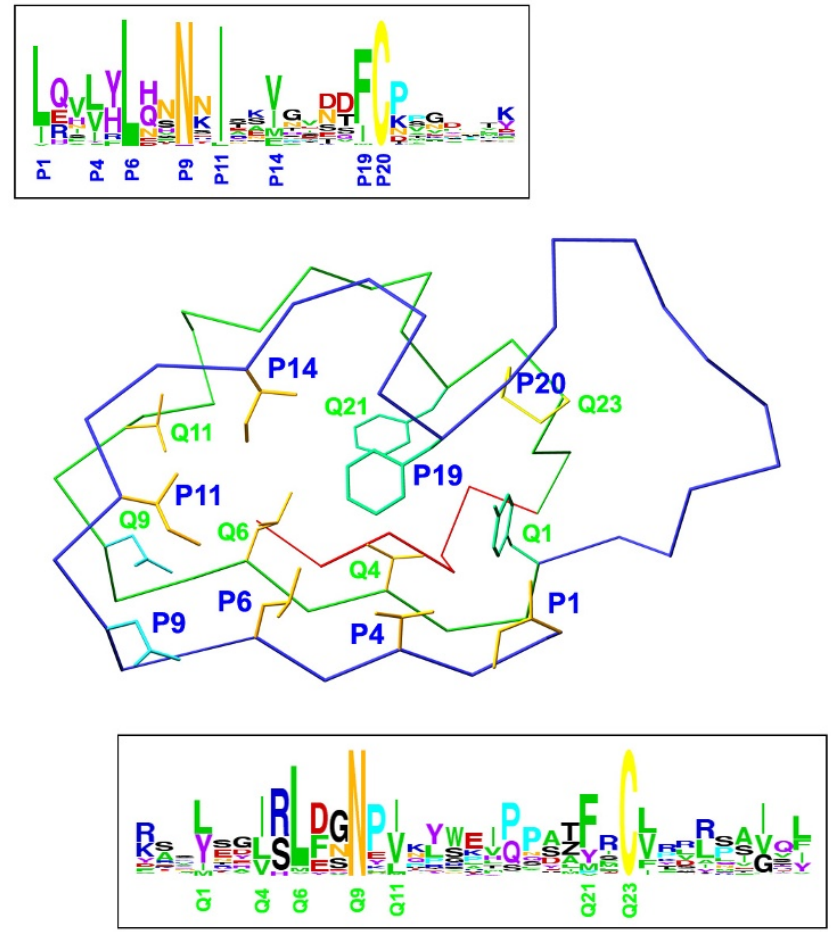

Figure 2

Mapping of the regular expression pattern of the LRRCE motif on a skeletal representation of the LRRCE structure from bovine decorin [29]. The motif includes the laterally extended ear repeat, shown as a $\mathrm{C} \alpha$ trace in blue, the following LRR (in green C $\alpha$ trace), and the final $\beta$-strand closing the domain (red $C \alpha$ trace). The regular expression pattern used in this study, written in PROSITE syntax [79], was: [LIV]-X(2)-[LVIYFMA]-X-[LIFM]-X(2)-[NH]-X[ILVF]-X(2)-[VIMFLY]-X(4)-[FIMLV]-C-X(7,20)-[LYIMV]$X(2)$-[ILVTMF]-X-[LVMI]-X(2)-N-X-[IVLMAFT]-X(8,9)[FYMPVAIS]-X-C. In PROSITE syntax each conserved position is shown either as a single amino acid (e.g. C, N) or all possible amino acids for that position enclosed within brackets (e.g. [ILVF] indicates that such position is occupied by lle, Leu, Val or Phe); each variable position is shown with a letter $X$. Numbers in parentheses indicate stretches of variable positions (e.g. $X(7,20)$ indicates a stretch of between 7 and 20 variable amino acids). Amino acid preferences for each position are shown in two boxes in "weblogo" form [87]. The conserved sequence positions for the ear repeat on the LRRCE motif are designated as PI, P4, P6,..., P20, and those for the following LRR as Q1, Q4, Q6,..., Q23. The side chains show the amino acids occurring at these conserved positons in the structure of bovine decorin.

at the N-terminus and the LRRCE capping motif at the Cterminus. The pattern was also comprehensive: all proteins known to belong to the canonical group of SLRPs or annotated as similar to them were retrieved in the search.
Sequences of LRRCE motifs from the UniProt non-redundant set were used in similarity searches with BLAST to retrieve additional LRRCE-containing sequences (see Methods). For most SLRPs, the LRRCE motifs are largely coded by the last exon from their corresponding genes. Thus, probe sequences just encompassing different LRRCE motifs were useful for quickly locating SLRP genes in genomes at early stages of annotation or for searching new SLRPs on the genomes of invertebrates and early chordates (see below). The extended list of 280 hits with their LRRCE sequences and accession codes, including those obtained from the NCBI and ENSEMBL databases, is provided in Additional File 1. The LRRCE regular expression pattern discussed earlier is consistent with all but seven of the sequences in this extended list. Three of these exceptions are incomplete sequences due to missing genomic data, and two more are predicted sequences with only one change with respect to the LRRCE pattern. Probably the only significant exceptions were the LRRCE sequences for the chicken and lizard homologues of ECM2, which contain an additional insertion (see Additional File 1). Many of the sequences found in similarity searches are from predicted model assemblies from genomes in early stages of annotation, and therefore some of the assignments should be considered preliminary.

\section{Structure of the LRRCE capping motif}

The LRRCE motif encompasses the ear repeat, which is extended laterally, the LRR following it, and the final $\beta$ strand closing the domain (Figure 2). The regular expression pattern runs from the beginning of the ear repeat to the second cysteine residue. Sequence conservation in LRRCE motifs across the different SLRPs follows largely structural dictates, with the highly conserved positions mainly corresponding to the core hydrophobic or asparagine residues characteristic of the LRR architecture, plus the two cysteine residues that are connected by a disulphide bond (Figure 2). Several additional positions show distinct preferences for polar or charged amino acids. The corresponding residues in the bovine decorin structure participate in a network of stabilizing charge-charge and hydrogen-bonding interactions between repeats. Thus, it is likely that similar interactions will be conserved in the other LRRCE-containing proteins to impart stability to the capping motif. Residue conservation in the ear itself is comparatively poor between closely related proteins (for example, between decorin and biglycan), but higher for the same protein across species (see examples in Figures 3 and Additional File 1). This pattern of conservation suggests that the ear extension contributes to the functional specialisation of the canonical SLRPs. For most sequences, the ear extension is 11-13 residues long (from the first cysteine to the first residue of the second LRR), and only keratocan and PRELP sequences show consistently long extensions. A buried lysine residue shown to stabilize the 


\begin{tabular}{|c|c|c|}
\hline & LRR1 & LRR2 \\
\hline ECM2_HUMAN & LHFLRLNNNKIRNII & ILHLENNYIKIREIPSYT \\
\hline ECM2_BOVIN & EQICNAEEDDD . . & HLHLENNYIKTREIPSYAI \\
\hline Q4TBJ8_TETNG & LHFLRLNNNQIRSVPEES ICDPDREGD . . . & LVVLRLENNYIDSKKISPSAFS \\
\hline Q1LXA8_DANRE & LHFLRLNNNKIRHVPEQAICDPLSEDD . . . & LVAVRLENNF IDPRKIPPTAFSCVRSYSSVVLKPQRIK \\
\hline Q1LYN3_DANRE & LQHLRLNHNY ISYVTMNSLCDTTARDD . . . . & LVSVHLEFNLIERRLIPPTAFS \\
\hline ASPN_HUMAN & LQIIFLHSNSIARVGVNDFCPTVPKMK. . . . & YSAISLFNNPVKYWEMOPATFI \\
\hline ASPN_BOVIN & LQIIFLHSNSITKVGVNDFCPTVPKMK. . . . & YSAISLSNNPVKYWEVQPATFR \\
\hline Q5XHD6_XENLA & LQVLFLHSNNIGKVDVNDFCPTGLKLK.... & YSGISLF KNPVKYWEVQPATFRCTLGRNSVHLGNFRK \\
\hline Q4TBJ7_TETNG & LQVIFLHGNKISKVGVNDFCPINPSTK.... & YSIISLFGNPVKYWEVNPVTFRCVTGRRS IHLGNFK \\
\hline Q6DBT8_DANRE & LQVMYLHANS IGYVGVNDFCPSRTRAK. . . & YTRISLYANPVKYWEIQPPTF \\
\hline PGS1_HUMAN & LQVVYLHSNNITKVGGNDFCPMGFGVK. . . . & YNGISLFNNPVPYWEVPPATF \\
\hline PGS1_BOVIN & LQVVYLHTNNITKVGVNDFCPVGFGVK. . . . & YNGISLFNNPVPYWEVQPATFR \\
\hline PGS1_XENLA & LQVVYLHSNNITQVGVNDFCPIGFGVK... . & YNGISLFNNPVPYWEVQPATFRCVTDRLAIQFGNYRK \\
\hline Q4T5R8_TETNG & LQVVYLHSNNIDHVGVNDFCPRGFGMK . . . & YNGISLFSNPVNYWEVQPATFRCVTDRLAIQFGNYKK \\
\hline Q6GMI5_DANRE & LQVVYLHSNNITNVGEDDFCPTGFGLK. . . & YNGISLFDNPIRYWEVQPSTFRCVSDQMAVQFGNHKK \\
\hline Q9DDZ8_PETMA & LQVVYLHSNKIAAVKSDDFCSKGASPK.... & GISLFDNPVNYWDVPPSAF \\
\hline PGS2_HUMAN & IQVVYLHNNNISVVGSSDFCPPGHNTK . . . & SGV̈SLFSNPVOYWEIOPSTE \\
\hline PGS2_BOVIN & IQVVYLHNNNISAIGSNDFCPPGYNTK . . . & GVSLFSNPVQYWEIQPSTFI \\
\hline PGS2_CHICK & IQVVYLHNNKIAS IGINDFCPLGYNTK. . . & SGVSLFSNPVQYWEIQPSAFR \\
\hline Q66J59_XENLA & IQVVYLHSNKIAAVSTNDFCPLGYNTK. . . & TGISLFSNPVQYWEIQPATFRCVYERSAIQIGNYK \\
\hline Q6J0Y6_PAROL & IQVVYLHVNKIAAVGTEDFCPPGFNTK... & SGISLF SNPVPYWEVQP ITFRCVFDRSAIQLGNYRKK \\
\hline Q5RI45_DANRE & IQVIYLHSNKIAAVGTEDFCPPGYNTK . . . & SGISLF SNPVPYWEVQPITFRCVFDRSAIQLGNYRKK \\
\hline LUM_HUMAN & LENYYLEVNQLEKFDIKSFCKILGPLS . . . & KHLRLDGNRISETSLPPDMY \\
\hline LUM & DVKSFCKILGPLS... & HLRLDGNHITQTSLPPDMYE \\
\hline LUM & LENFYLQVNKINKFPLSSFCKVVGPLT... & ITHLRLDGNNLTRADLPQEMYN \\
\hline Q7SYS8_XENLA & LENLYMQVNKIQKFTLNSFCKVIGPLE. . . & IRHLRLDGNNISRIDLPQDMYS \\
\hline Q6IQQ7_DANRE & LEHLYLQVNE INKFELTNI & LRQASEIIFE \\
\hline FMOD_HUMAN & LENLYLQGNRINEFSISSFC̈TVVDVV . . & VVRLDGNEMKRSAMPAEAPI \\
\hline FMOD_BOVIN & LENLYLQGNRINEFSISSFCTVVDVM. . . . & QVQRLDGNE IKRSAMPADAPL \\
\hline FMOD_CHICK & LENLYLQGNQINEFSISSFCTVVDVM. . . . & QVLRLDGNEI KRNAMPPDAPL \\
\hline Q4V9E0_DANRE & LQHLYLQANQIKEFTLGSFCSVVDVM. . . . & RVLRLEGNEIGAGDVPSEAAI \\
\hline OMD_HUMAN & LEHLYLQNNE IEKMNLTVMCPSIDPLH . . . . & YIRVDQNKLKE.PISSYIF \\
\hline OMD_BOVIN & NVTVMCPSVDPLH... & HIRIDQNKLKA.PISSYI \\
\hline Q1LV49_DANRE & LEHLYLNHNDFKD & PRLIMIFYGHQRK. . . \\
\hline KERA_HUMAN & LQHLHLDHNKIKSVNNVSVICPSPSMLPAERL & RYLRLDGNEIKP.PIPMALN \\
\hline KERA_BOVIN & LQHLHLDHNKIRNVNVSVICPSTPTTLPVED. & ILRYLRLDGNE IKP. P IPMDLMTCFRLLQAVII \\
\hline KERA_CHICK & LEHLHLDHNR IKS VNGTQICPVSIAVAEDYGL & LRYLRLDGNEIQP. PIPLDIMICFQLLQAVVI \\
\hline Q5RI43_DANRE & LEHLHLDHNKIKSVNSSDICPPGVLDDH . . . & LRYLRLDGNEIQP . PIPRELMTCFRLLRAVVI \\
\hline PRELP_HUMAN & LEHLYLNNNS IEKINGTQICPNDLVAFHDFS & YLRLDGNYLKP.PIPLDLM \\
\hline PRELP_BOVIN & LEHLYLNNNSIEKINGTQICPNNIVAFHDFSS & RYLRLDGNYLKP · PIPLDLM \\
\hline A4IIL_0_XENTR & LEHLYLNDNI IEKINGTEICPAPLVPFDFSSR & LRYLRLDGNQLKP.PIPLDVI \\
\hline A8BBF7_DANRE & LEQLHLNNNNIESVNGTEICPPHNVHDE. . . & RYLRLDGNHLSP. PVPLDV \\
\hline MIME_HUMAN & LRVIHLQFNNIASITDDTFCKANDDTSYI . . & EEIRLEGNPIVLGKHPNS.F \\
\hline MIME_BOVIN & LRVI HLQFNNITTSITDDTFCKANNDTSYI. . & IEEIRLEGNPVILGKHPNS.FICLKRLPIGSYI \\
\hline MIME_CHICK & LRILHLQHNNITTINDDTFCKSNNTRYI. . & MDEIRMEGNP ILLAKHVNA. FSCLRTLPVGTYY \\
\hline Q7ZYH2_XENLA & LKILHLQQNNITSITDDTFCKSNDTRY I . . & MAEIRMEGNPVILGKHPNS.FTCLKTLPSGSYFK \\
\hline Q4T4G9_TETNG & LHIVHLNNNKIAAITDETFCKGNTSYYV... & MDEVRLDGNPVVLANYPYS.FICLKSLPVGWYN \\
\hline Q1LV51_DANRE & VRTLHLQNNNIISTVSTDTFCKSNDDTYYI. . . & INEIRMD GNP INLGQYPNS F FCLQSLPIGRYQ \\
\hline OPT_HUMAN & LRSVHLQNNLIETMORDVFCDPEEHKHT . . & EDIRLDGNPINLSLFPSA. Y \\
\hline OPT_BOVIN & LRSLHLQNNMIETMQRDAFCDAEEHRHT. . & EDIRLDGNPINLSLFPSA. YFCLPRLPTGRFV \\
\hline Q6YEX8_CHICK & LRSLHLQNNNIQTMHEDTFCNSQDQSHV. . . & EDIRLDGNPINLSLFPNA. YFCLPRLPTGHFL \\
\hline Q66KS3_XENLA & LQSLHLQDNNIQEMHEDTFCKMKDWTYA. . . & EDIRLDGNPIÑLSRTPQA. FMCLPRIPIGRLV \\
\hline Q15JE7_DANRE & LRVLHLQNNNIQSITQDTFCNSHDKNY I... & EDIRLDGNPVDINLYPQA. YFCLPRLPVGTPV \\
\hline EPYC_HUMAN & LRALHLQNNNILEMHEDTFCNVKNILTYI. . & EDIRLDGNPINLSKTPQA. YMCLPRLPVGSLV \\
\hline EPYC_BOVIN & LRALHLQNNN IMEMHEDTFCNVKNLTY I . . & LEDIRLDGNPINLSKTPQA. YMCLPRLPIGSLV \\
\hline EPYC_CHICK & LQALHLQNNNIQEMHEDTFCKMRDFSYV. . . & LEDIRLDGNP INLSKTPYA. YMCLPRLPVGNLI \\
\hline Q66KS3_XENLA & LQ̈SLHLQDNNIQEMHEDTFCKMKDWTYA. . . . & LEDIRLDGNPINLSRTPQA. FMCLPRIPIGRLV \\
\hline Q4SBV0_TETNG & LRSLHLQRNNIQSMHEDTFCNLKDFNY I . . . & LEDIRLDGNPINLSRTPQA. YICLPRIPIGDLV \\
\hline Q568A7_DANRE & LRSLHLQNNNIQMIHEDTFCNPHDLNY I . . & LEDVRLDGNPINLSRTPQA. YICLPRIPIGNLF \\
\hline $\begin{array}{l}\text { Ciona intest. } \\
\text { Ciona savig. }\end{array}$ & $\begin{array}{l}\text { LEALFLESNQIFSVQIDSFCPMNPERFV... } \\
\text { LEALFLESNQIFSVQIDSFCPMNPDRFV... }\end{array}$ & LHTLRLDGNLIDSNDLPALAFYCL. SSMEVVVTT \\
\hline
\end{tabular}

Figure 3

Multiple sequence alignment of LRRCE motifs from a selected set of SLRP sequences from the UniProt nonredundant set. Names for the sequences are those of their corresponding Swiss-Prot or TrEMBL entries. Members of the different classes are shown with their names in green (class I), blue (class II), red (class III) or black (ECM2 and similar proteins). Two sequences from early SLRPs in urochordates (Ciona intestinalis and Ciona savigny) are also included with their name in magenta (see text). The boxes on the top indicate the two consecutive repeats LRRI and LRR2 that contain the LRRCE motif. The ear itself is included in the first repeat. Residue conservation colour scheme: conserved cysteines in red; conserved residues in yellow; partially conserved residues in green; conserved prolines in cyan; polar residues in conserved hydrophobic sites in magenta; potential sites of $\mathrm{N}$-linked glycosylation in blue. 
ear conformation in the crystal structure of decorin [29] is conserved as lysine or arginine in all class I and III sequences, whereas in class II sequences the same position is occupied by an aromatic or leucine residue. Fibromodulin, osteoglycin and epiphycan sequences show conserved $N$-linked glycosylation sites in their ear extensions. Additional potential $\mathrm{N}$-linked glycosylation sites appear with varying degrees of conservation on different regions of the two repeats forming the LRRCE motif.

\section{LRRCE motifs are always C-terminal}

The LRRCE motif is a genuine C-terminal motif, with no instance of an equivalent architecture in the middle of an LRR domain or protein. The C-terminus is typically 9-15 residues away from the conserved second cysteine. The exception is the group of OMD sequences, which contain an extended C-terminal tail of about 60 residues after the LRRCE motif. This tail contains a stretch of negatively charged residues that presumably shares some functional role with the negatively charged glycosaminoglycan chains attached to the $\mathrm{N}$-termini of decorin or biglycan, or the polyanionic stretches seen in the $\mathrm{N}$-terminal region of asporin or preceding the LRR domain in ECM2.

The LRRCE motif can be related structurally to internal, disulphide-bonded LRR pairs that occasionally occur in LRR proteins. These LRRs do not show the lateral extensions characteristic of the LRRCE motifs. These intradomain, disulphide-bonded LRR pairs are much more widely distributed than LRRCE, as they occur in different LRR protein families from bacteria to humans. One such linkage can be seen in the three-dimensional structure of the ectodomain of Toll-like receptor $3[49,50]$. This structure is formed by a tandem of 25 LRRs capped by LRRNT and LRRCT motifs, and contains one internal disulphidebonded LRR pair.

\section{The LRRCT and LRRCE structural motifs appear to be unrelated}

There is no obvious relation between the LRRCT and LRRCE motifs, at least from sequences available to date. A conserved feature in the LRRCT capping motif is the presence of two or more Trp residues that contribute to maintain the hydrophobic core at the C-terminal end. A common sequence at the beginning of LRRCT motifs is $\mathrm{NPW} x \mathrm{C} x \mathrm{C} x_{3} \mathrm{~W} x_{3} \mathrm{~W}$, where the second and third Trp residues are located on the inner side of the $\alpha$-helix characteristic of the LRRCT structure (Figure 1b). Conversely, Trp residues are not particularly conserved in the LRRCE sequences (Figure 3 and Additional File 1), and the only Trp residue in the structure of bovine decorin [29] is exposed to the solvent and does not participate in the hydrophobic core of the C-terminal end of the LRR structure.

\section{A new class of canonical SLRPs, with sequences similar to ECM2}

A cluster analysis of the extended set of LRRCE-containing sequences is shown in the form of a phylogenetic tree inferred from a multiple sequence alignment of the LRRCE motifs (Figure 4 and Additional File 2). The sequences group themselves in the canonical SLRP classes (I, II and III), plus an additional cluster containing ECM2 and related sequences. Class I includes asporin (ASPN), decorin (DCN) and biglycan (BGN) sequences. Class II contains two groups and could in fact be subdivided into IIa with lumican (LUM) and fibromodulin (FMOD) sequences, and IIb with osteomodulin (OMD), keratocan (KERA) and prolargin (PRELP) sequences. Class III includes sequences for opticin (OPTC), epiphycan (EPYC) and osteoglycin (OGN), also known as mimecan.

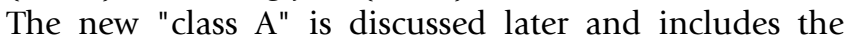
sequences of extracellular matrix protein 2 (ECM2), ECM2-like protein from the $\mathrm{X}$ chromosome (ECMX), ECM2-like predicted proteins upstream of the DCN gene in fish genomes (ECMZ), and the small leucine-rich repeat protein from Ciona intestinalis and Ciona savignyi (SLRP1) (see below). The same clustering was obtained using the complete SLRP sequences (not shown), indicating that the LRRCE sequences on their own are useful for canonical group SLRP classification.

\section{The LRRCE motif is unique to chordates}

Given the exclusive vertebrate lineage of all sequences obtained in the UniProt set, searches with LRRCE sequences were carried out against several invertebrate genomes including Drosophila melanogaster (fruit fly), Apis mellifera (honeybee) [51], Anopheles gambiae (malaria mosquito), Aedes aegypti (yellowfever mosquito) [52], Caenorhabditis elegans (worm) and Strongylocentrotus purpuratus (sea urchin) [53]. Of particular interest was the genome of the sea urchin, as this organism appears to have retained some of the genes later observed only in vertebrates [53]. All the genomes investigated have large numbers of LRR proteins, many of those with LRRNT capping motifs. However, the searches failed to produce any true match of LRR proteins containing LRRCE motifs in these invertebrate genomes. Two LRR protein sequences from mosquito (Q16VM2_AEDAE and Q17NB1_AEDAE in TrEMBL) are currently annotated (incorrectly) as putative lumicans, although they lack recognizable LRRNT caps and neither their repeat lengths nor amino acid sequences correspond to those of lumican proteins. Nonchordate LRR protein sequences are often homologous to non-SLRP proteins such as toll-like receptors or slit proteins, and C-terminal disulphide-capping often occurs through the more common LRRCT type. 


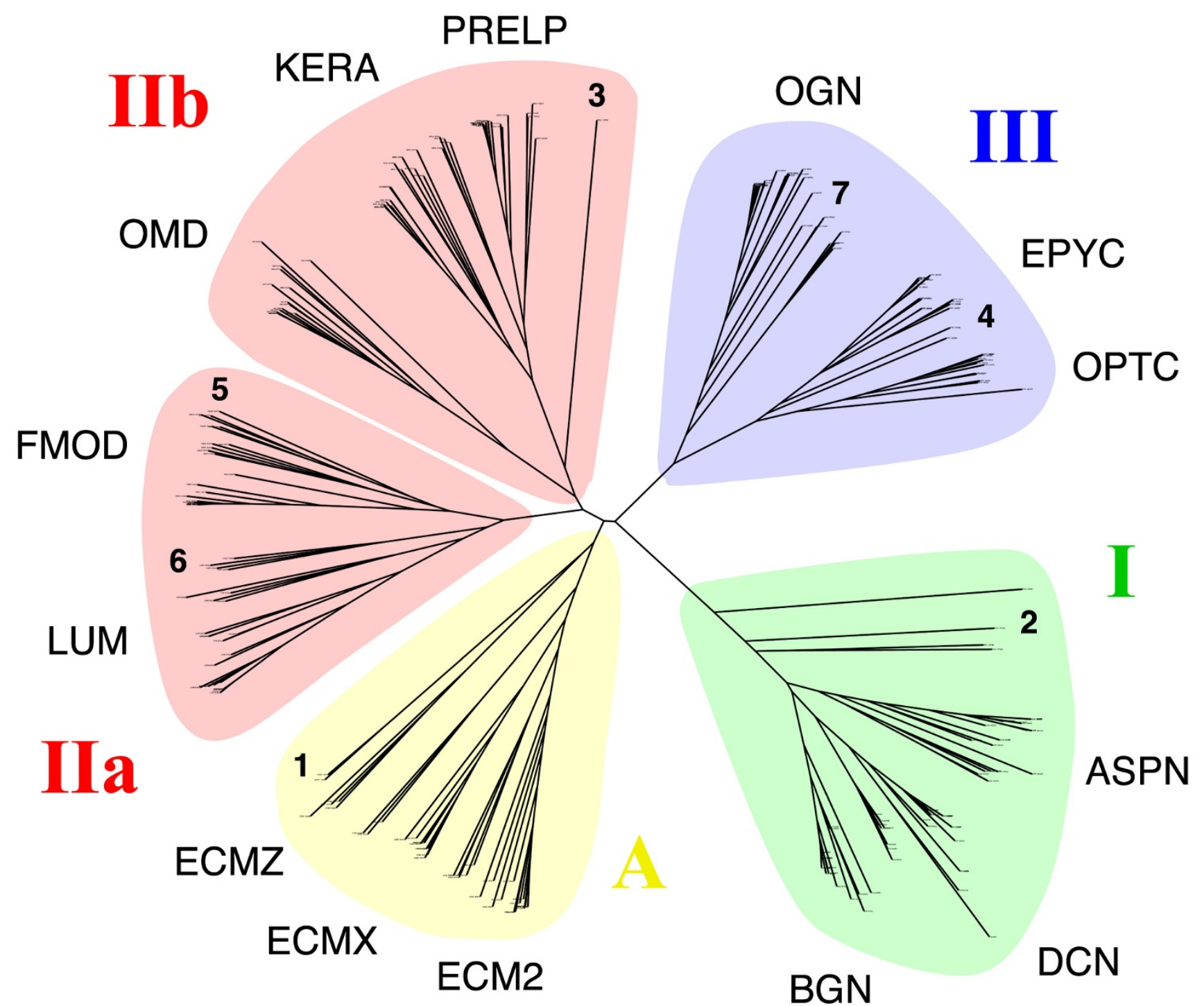

Figure 4

Unrooted phylogenetic tree of an expanded set of LRRCE-containing sequences, including those from UniProt, NCBI and ENSEMBL databases. Sequences group themselves in four main SLRP classes, and the class II branch has been split into two subclasses Ila and Ilb. See text for the abbreviations describing each SLRP type. The positions of several sequences specifically discussed in the text are indicated with bold-type numerals: I, SLRPI sequences from Ciona intestinalis and Ciona savignyi; 2, biglycan-like (BGL) and decorin-like (DCL) sequences from sea lamprey Petromyzon marinus; 3, keratocanlike (KERAL) sequence from lamprey; 4, epiphycan-like (EPYL) sequence from lamprey; $\mathbf{5}$, cluster of second copies of fibromodulin (FMOD2) exclusive to fish genomes; 6, cluster of second copies of lumican (LUM2) exclusive to fish genomes; 7, cluster of second copies of osteoglycin (OGN2) exclusive to fish genomes. This tree was calculated based on the sequence alignment of the LRRCE motifs. A larger version of this figure, with legible sequence names at the end of the phylogenetic tree branches, is provided as Additional File 2.

\section{LRRCE motifs in early chordates: implications for SLRP} evolution

Similarity searches using LRRCE sequences were then carried out against the genomes of the early chordates amphioxus (lancelet), Branchiostoma floridae [54], and the ascidians Ciona intestinalis [55] and Ciona savignyi [56].
Only one gene containing the LRRCE motif was found for each Ciona species. This gene, referred to here as SLRP1, has been proposed as representative of the ancestor of all modern canonical SLRPs [57]. Two model assemblies have been proposed for the Ciona intestinalis gene resulting in proteins with different numbers of LRRs (Figure 5). 


\section{SLRP1 from Ciona intestinalis}

\begin{tabular}{|c|c|c|c|c|}
\hline \multirow[t]{4}{*}{$L R R$} & Long assembly model & $N$ & Short assembly model & $N$ \\
\hline & MRFFSQVTLFLCIAVLCTSPTTFGSRFKRGSRRQ & & & \\
\hline & PVLFN & & IIPLDPESPLSPS & \\
\hline & RYICPPQCACS & & YICPPQCACS & \\
\hline I & LNIIYCSGKQLNEIPSTFPRN & 21 & LNIIYCSGKQLNEIPSTFPRN & 21 \\
\hline II & GEFLHLENNYITRIHSGVFRHFPA & 24 & GEFLHLENNYITRIHSGVFRHFPA & 24 \\
\hline III & IQRIILTKNRLISAGLKARSFEGLTA & 26 & IQRIILTKNRLISAGLKARSFEGLTA & 26 \\
\hline IV & LKRLDLSENKLTRFPRSLPPS & 21 & LKRLDLSENKLTRFPRSLPPS & 21 \\
\hline $\mathrm{V}$ & LVELRLNLNNITKVKRGATRGLTN & 24 & LVELRLNLNNITKVKRGATRGLTN & 24 \\
\hline VI & LVALSLFRNSITDAGFEPAILKNMTA & 26 & LVALSLFRNSITDAGFEPAILKNMTA & 26 \\
\hline VII & LSYLDLNENLLETVPQGLPES & 21 & LSYLDLNENLLETVPQGLPES & 21 \\
\hline VIII & LREIRLENNGLKNVTÄGIFTSQSL & 24 & LREIRLENNGLKNE INYKTFISSLN & 25 \\
\hline IX & LHHFSLRNNQLSDQGINFNAWSNMSN & 26 & LTQIKLSFNKIRIITPGSFTRLIH & 24 \\
\hline $\mathrm{x}$ & LFLLDLSYNKLRT IPRGLPPS & 21 & LRFLDLAFNNLLYVPRGLPTT & 21 \\
\hline $\mathrm{XI}$ & 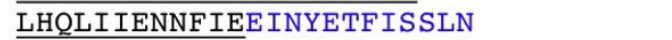 & 24 & LEALFLESNQIFSVQIDSFCPMNPERFVTSK & 31 \\
\hline XII & 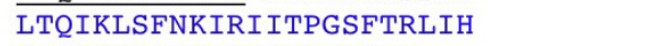 & 24 & LHTLRLDGNLIDSNDLPALAFYCLSS & 26 \\
\hline XIII & LRFLDLAFNNLLYVPRGLPTT & 21 & .MEVVVT & \\
\hline XIV & LEALFLESNQIFSVQIDSFCPMNPERFVTSK & 31 & & \\
\hline $\mathrm{XV}$ & $\begin{array}{l}\text { LHTLRLDGNLIDSNDLPALAFYCLSS } \\
\text {. MEVVVT }\end{array}$ & 26 & & \\
\hline
\end{tabular}

\section{Figure 5}

Two different gene assembly models for the only LRRCE-containing sequence in Ciona intestinalis. Sequences encoded by separate exons are shown in different colours (red-black-blue) for clarity. The long model assembly (left) contains 8 exons and I5 LRRs in its LRR domain. The same gene assembly model is used for the homologous protein in Ciona savigny. The short model assembly on the right contains 7 exons and I 2 LRRs in its LRR domain; one and a half exons are skipped resulting in the removal of the underlined amino acids from the long form. Both models were generated using prediction algorithms. The short model was part of the first draft for the Ciona intestinalis genome [55] (JGI assembly version I.0, cil48I60), but was later withdrawn in JGI version 2.0 in favour of the longer model. Available EST data (see gene and transcript entries ENSCING000000 I 2194, ENSCINT00000023 I 42 in the ENSEMBL database), has confirmed the long assembly model with I5 LRRs.

These two assemblies only differ in the prediction of one additional exon-intron boundary in the short model, which results in the skipping of one and a half exons from the long model. The long model assembly for the Ciona intestinalis SLRP1 gene has been confirmed by EST data (Figure 5). The resulting protein sequence has 15 LRRs in which repeats alternate their lenghts following a predominant 21-24-26 pattern; this repeat structure is very similar to that seen in the ECM2 sequences from vertebrates [32]. The cluster analysis of LRRCE motifs (Figure 4) places the SLRP1 sequences of Ciona intestinalis and Ciona savigny in the same group as ECM2 and related sequences. The alternating pattern of repeat lengths (21-24-26) is common to SLRP1 as well as a Ciona gene representative of the podocan ancestor [57], suggesting that such an alternating repeat sequence was already present in a common precursor of these two lineages. This observation is consistent with the concept of tandem LRR supermotifs characteristic of the evolutionary history of the SLRP family [58].
An interesting possibility is that shorter, 12-LRR SLRPs (such as these from classes I and II), originated by exon skipping from an ancestral SLRP gene with 15 LRRs similar to SLRP1 from Ciona, in a manner illustrated by the short model assembly shown in Figure 5. Such exon skipping would have occurred after duplication of this ancestral SLRP gene. The two genes could have later evolved after additional tandem and large-scale duplication events into two independent lineages, one for ECM2 and ECM2like proteins (discussed below), and another for the class I and class II SLRPs. Class III SLRPs would have originated by further exon skipping on the class I and II ancestor, after its divergence from the ECM2 lineage ancestor.

No gene containing an LRRCE motif could be detected in the currently available release of the amphioxus genome (Branchiostoma floridae, JGI version 1.0) [54]. Sequence similarity searches using the protein sequences of the three SLRP proteins from Ciona (Figure 5 and [57]) pro- 
duced putative orthologues of podocan and chondroadherin (data not shown), and partial hits to many nonSLRP protein sequences with LRR architecture (several cell-surface receptors, slit-like proteins, etc). However, the searches failed to return any clear orthologues of the canonical SLRPs or any sequence containing a LRRCE motif. Queries using sequences conforming to LRRCE motifs from Ciona yielded no hits either. The apparent absence of LRRCE-containing genes in Brachiostoma is intriguing. Cephalochordates (amphioxus) have been traditionally considered to be the primitive chordates that most resemble vertebrates, but this view has been very recently contradicted by the genome sequence data that suggests that tunicates (which include the ascidians), are more closely related to vertebrates than cephalochordates [59]. This finding raises the possibility that the first LRRCE-containing SLRP genes appeared after the divergence of cephalochordates from the rest of the tunicatevertebrate lineage. Alternatively, the gene equivalent to SLRP1 from Ciona was already present in a common ancestor of all chordates but may have been lost in the cephalochordate lineage.

\section{Agnathans show already an expanded set of SLRP sequences}

Searches for LRRCE motifs against the current release of the sea lamprey genome Petromyzon marinus (Genome Sequence Center, Washington University) produced six LRRCE-containing sequences. Two of them correspond to previously reported biglycan-like proteins [60], whereas the four additional hits correspond to predicted partial sequences similar to decorin (two sequences), epiphycan (one sequence) and keratocan (one sequence). We have named these sequences biglycan-like proteins 1 and 2 (BGL1 and BGL2), decorin-like proteins 1 and 2 (DCL1 and DCL2), epiphycan-like protein (EPYL) and keratocan-like protein (KERAL) (Table 2). Although these data should still be considered preliminary, the sequences represent the earliest examples to date of class I, II and III SLRPs, suggesting that the divergence of the SLRP ancestor into three classes, following gene duplication, occurred before the lamprey-gnathostome split. Completion of the lamprey genome and possible identification of additional copies of EPYL and KERAL genes will clarify the relation between individual SLRP gene duplications and the largescale gene or genome duplication that is thought to have

Table 2: Representative examples of class I, II and III SLRP sequences in sea lamprey.

\begin{tabular}{|c|c|c|c|c|}
\hline LRR & BGL2_PETMA (class I) & $N$ & KERAL_PETMA (class II) & $N$ \\
\hline & ...PDASCPFGCQCS & & ...PPLCPVACYCPPDH & \\
\hline I & ARVVQCSDLGLVSVPQAIPKD & 21 & PGAIYCDGRELHDVPRIPAR & 20 \\
\hline II & ARLLDLQNNKITEIKQDDFKGLNK & 24 & VRFAYFQNNNIEALSECDLRDAGG & 24 \\
\hline III & LYALYLVNNLISKVHPKAFAPLSS & 24 & LLGLNLDDNVLTSPTLSQDTLRSLRH & 26 \\
\hline IV & LDKLYISHNQLTEVPGSMPSS & 21 & LSQLHLQRNQLTEVPLGLPAS & 21 \\
\hline$\vee$ & LVELRIHENNIKKIPKDAFSGMKR & 24 & LEDLRLGQNRIALVPKGAFARLSR & 24 \\
\hline $\mathrm{VI}$ & LHALEMGGNPLQSTGIEVGAFEGLER & 26 & LRMLDLSANRLQVLRDDAFAGLSA & 24 \\
\hline VII & LVYVRVSDSKLARIPKDLPNS & 21 & LVQLNLAENRLRAMPPKPPSGL & 22 \\
\hline VIII & IQELHLEHNQITALEQEDLIRYPL & 24 & LYQLILCDNVIESIPDNYLASFPR & 24 \\
\hline IX & IHRLGLSYNQIKVIQNGSLETCPH & 24 & LAWLDLGKNALGTRREKRTGIPERAFISRA & 30 \\
\hline $\mathrm{X}$ & LRELHLDSNVLTQVPPGLAFLKH & 23 & LLNLRLSANHLQHVPAFHGN & 20 \\
\hline $\mathrm{XI}$ & LQVVYLHSNKIAAVKSDDFCSKGASPKRVL & 30 & LVQLHLDENDIEDVNTTALCRPEGRESSR & 29 \\
\hline XII & $\begin{array}{l}\text { YSGISLFDNPVNYWDVPPSAFRCVASR } \\
\text {.SAVQFSQNFRK }\end{array}$ & 27 & $\begin{array}{l}\text { LSYFRLDKNPIMESPQAPLMHCFPY } \\
\text { LQPMF }\end{array}$ & 25 \\
\hline \multirow[t]{2}{*}{ LRR } & EPYL_PETMA (class III) & $\mathbf{N}$ & & \\
\hline & ...MPTCLLCSCV & & & \\
\hline 1 & HGSVYCDDLELDSVPPLPKD & 20 & & \\
\hline II & TVYLYARFNKIRTLRKKDLSGYAQ & 24 & & \\
\hline III & LKRVDLSSNGLTSVEAGALAQLPA & 24 & & \\
\hline IV & LEEVLLAGNELVALPELPPA & 20 & & \\
\hline$\vee$ & TRRLDARQNHVTSKGVAADMFEKMKQ & 26 & & \\
\hline VI & LEYLYLSDNQLDFIPVPLPDS & 21 & & \\
\hline VII & LRVLHLQNNNIQQIREDTFCKPKELSYFRKA & 31 & & \\
\hline VIII & $\begin{array}{l}\text { LEDVRLDGNPVNLSDAPEAYTCLPR } \\
\text { IPTGATF }\end{array}$ & 25 & & \\
\hline
\end{tabular}

Repeats are numbered in roman numerals, and $N$ is the length of each repeat. Sequences amino terminal to the LRRNT cluster have not been included. 
occurred before the divergence of lampreys from gnathostomes $[57,61,62]$.

\section{The LRRCE motif is a useful annotation tool for extending the SLRP family}

The LRRCE capping motif is useful in sequence annotation as it appears to be exclusive to the canonical group of SLRPs. The presence of an LRRCE motif in a newly predicted protein sequence is sufficient for its quick identification and classification as a member of the canonical group of SLRPs (and also into one of its classes). The amino acid sequences of LRRCE motifs can be used as probes in similarity searches against translated genomic databases (TBLASTN). These searches can identify the locations and partial sequences of new putative SLRP genes in genomes at different levels of completion (as shown with the lamprey example). Using these probes, it is also possible to detect exons or domains that are missing in current assembly models of SLRP genes but nevertheless present in the genome (data not shown).

Figures $6,7,8,9,10$ show partial phylogenetic trees for each SLRP class, inferred from multiple sequence alignments of LRRCE-containing sequences from a subset of genomes (see Methods). Not all SLRP sequences have been found in all genomes. This could be owing to incomplete coverage in some of these genomes or to genuine absence of particular genes due to gene loss. For example, it has been known for some time that chickens do not have a BGN gene [63], and unsurprisingly no such gene has been found in searches against the chicken genome. Interestingly, the BGN gene is present in fishes, reptiles and mammals. The genomes of ray-finned fishes (zebrafish, stickleback, medaka, and the pufferfishes) appear to have an extended set of SLRPs, with additional copies of fibromodulin (FMOD2), lumican (LUM2), osteoglycin (OGN2) or biglycan (BGN2) genes (Figures 6, 7, 8,9 ), and yet seem to have mostly lost the genes for OMD and OPTC (with the exception of zebrafish, which appears to have retained a particularly complete set of SLRP genes).

\section{Newly predicted SLRP sequences related to ECM2 in fishes and mammals}

Several ECM2-like genes have also been predicted both in fishes and mammalian genomes (Figures 4 and 10; see also Additional File 1 for sequences and accession codes). A particularly interesting example is that of a protein sequence similar to ECM2 that was first predicted in the genome of zebrafish (Danio rerio, accession codes Q1LYN3, XP_690561).

This sequence, referred to here as ECMX for reasons explained later, is predicted upstream of the biglycan gene (Figure 11), in a completely analogous manner to the

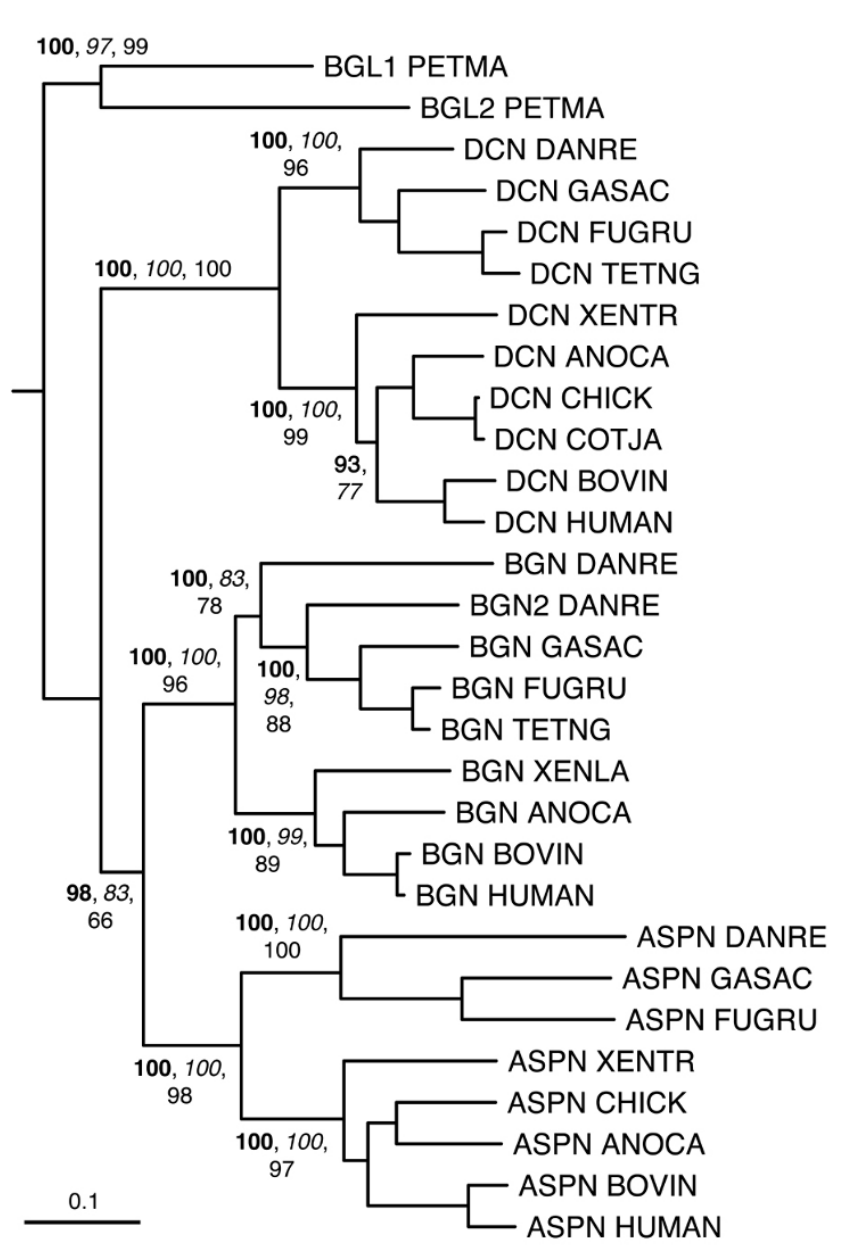

Figure 6

Phylogenetic relationships of class I SLRPs, inferred from the multiple sequence alignment of LRR domains from a reduced set of SLRP sequences (see Methods). The tree has been rooted using the BGL lamprey sequences as outgroup. $A$ second $B G N$ sequence (BGN2) has been identified in the zebrafish genome but not yet in other fishes. Clade proability values higher than $60 \%$ are indicated, bayesian estimates in bold-type, neighbor-joining in italics, and maximum-likelihood in roman type. Probability values for the fine structure in each clade are not shown for clarity. The scale bar represents amino acid substitutions per site.

ECM2-ASPN gene tandem seen in mammalian and fish genomes (Figure 11). The predicted ECMX sequence for zebrafish (Table 3 ) shows a LRR structure highly similar to ECM2, with 15 LRRs and a sequence of repeat lengths highly reminiscent of the 21-24-26 pattern mentioned earlier.

Most interestingly, reciprocal interrogation of the human genome using the LRRCE motif from the zebrafish ECMX sequence gave a hit in chromosome $\mathrm{X}$ (accession code 


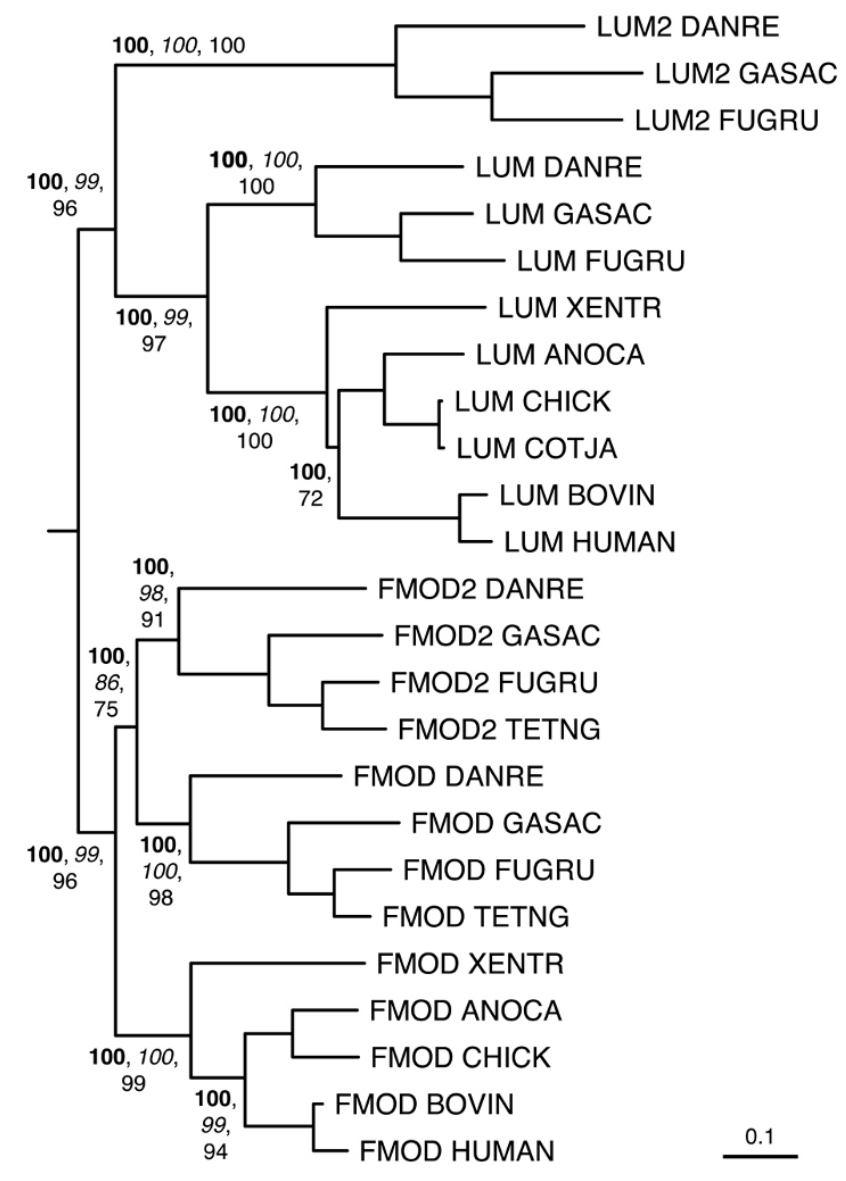

Figure 7

Phylogenetic relationships of class Ila SLRPs, inferred from the multiple sequence alignment of LRR domains from a reduced set of SLRP sequences (see Methods). The tree has been rooted using the midpoint method. Sequences group into two main clusters corresponding to class Ila SLRPs: fibromodulins FMOD and FMOD2, and lumicans LUM and LUM2. The second copies FMOD2 and LUM2 are only present in genomes of ray-finned fishes. Clade probability values higher than $60 \%$ are indicated as in Figure 6. The scale bar represents amino acid substitutions per site.

XP_001714654, currently known as hypothetical protein LOC389904), upstream of the human biglycan gene (Xq28). The predicted protein sequence of this putative novel SLRP is highly similar to the ECMX sequence from zebrafish, although different alternate model assemblies have slightly different number of repeats. This hypothetical protein, which we have named here ECMX owing to its similarity in repeat structure to ECM2 and its location in the $\mathrm{X}$ chromosome, has orthologues predicted in the genomes of orangutan, macaque, bovine, horse, dog, opossum (Monodelphis domestica), platypus (Ornithorhyn-

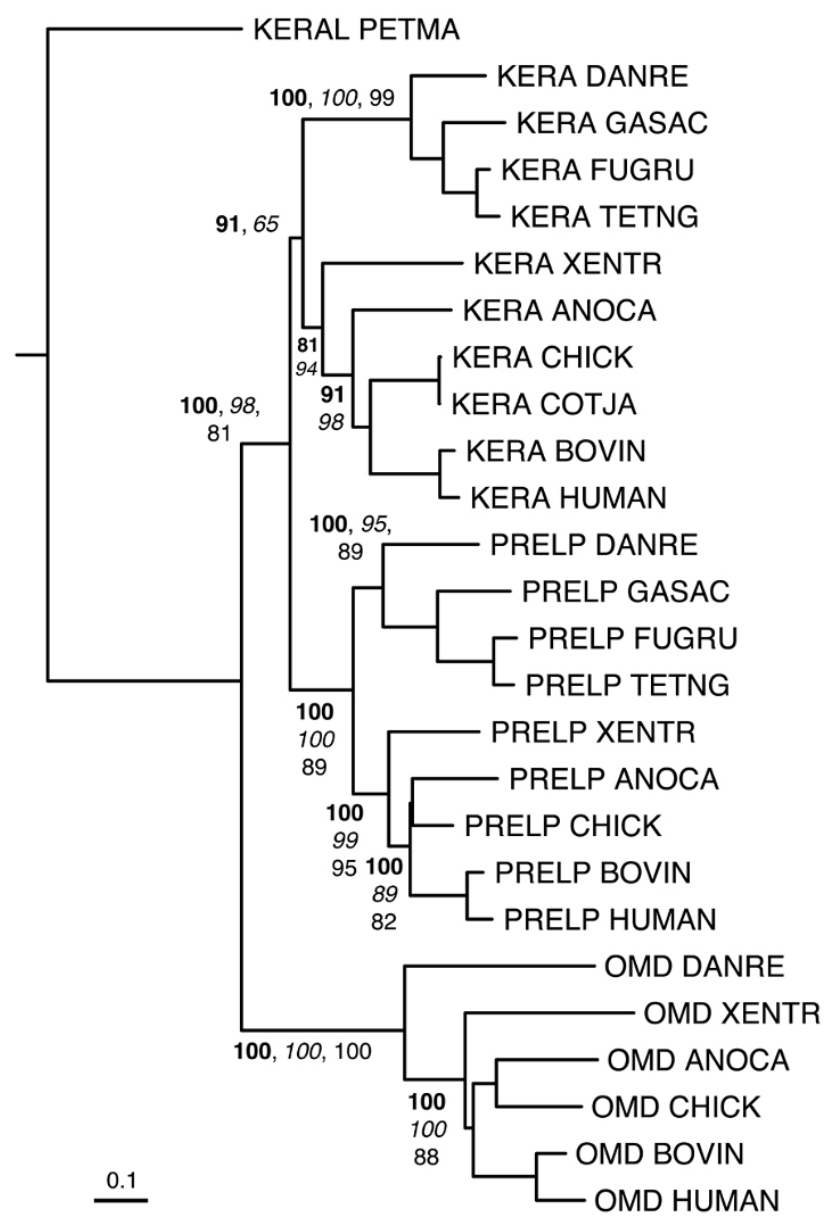

Figure 8

Phylogenetic relationships of class Ilb SLRPs, inferred from the multiple sequence alignment of LRR domains from a reduced set of SLRP sequences (see Methods). The tree has been rooted using the lamprey sequence as outgroup. Clade probability values higher than $60 \%$ are indicated as in Figure 6. The scale bar represents amino acid substitutions per site.

chus anatinus), frog (Xenopus tropicalis), and several fishes (zebrafish, Gasterosteus aculeatus, Oryzias latipes, Takifugu rubripes and Tetraodon nigroviridis). The predicted sequence of the horse orthologue (Table 3) maintains the same repeat structure as the zebrafish one. Currently, it is unclear if the differences in repeat structure with the predicted human sequence are significant or if some of the predictions are partially incorrect. Partial transcription evidence for ECMX in humans (EST data) has been obtained from osteoarthritic cartilage and chondrosarcoma (accession codes BQ181183, BQ447619, BQ448435, BQ772123). There is also EST evidence for ECMX in zebrafish (accession codes EB980280, CR929461), Gasterosteus aculeatus (DW649744, 


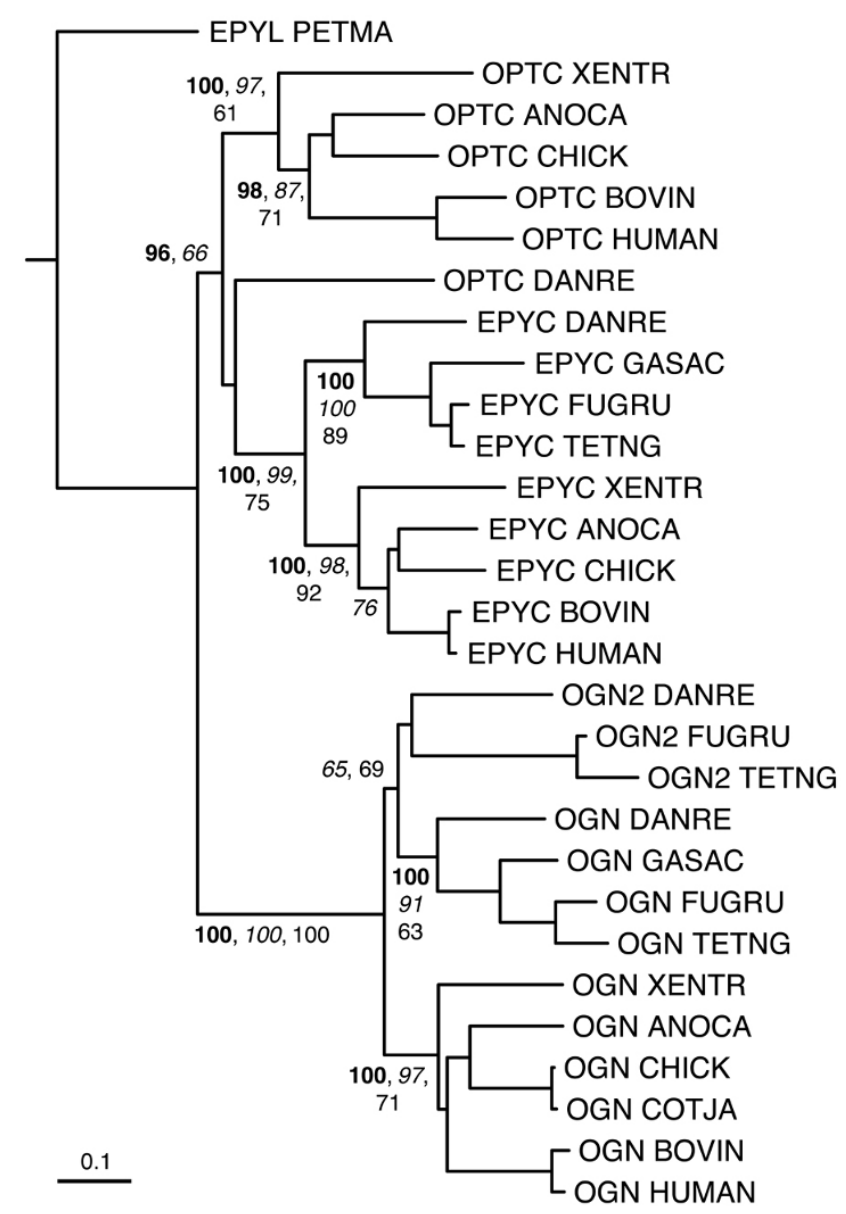

Figure 9

Phylogenetic relationships of class III SLRPs, inferred from the multiple sequence alignment of LRR domains from a reduced set of SLRP sequences (see Methods). The tree has been rooted using the predicted epiphycan-like (EPYL) sequence from lamprey as outgroup. Sequences cluster into three main groups corresponding to class III SLRPs: opticin, epiphycan, and osteoglycins OGN and OGN2. The second copy OGN2 is only present in genomes of ray-finned fishes, whereas the gene for OPTC appears to have largely disappeared from fish genomes, the only known example so far being that of zebrafish. Clade probability values higher than $60 \%$ are indicated as in Figure 6 . The scale bar represents amino acid substitutions per site.

DW649745), and Xenopus tropicalis (CN119819, CX371080, CX409086).

A second ECM2-like predicted sequence occurs upstream of the decorin gene in the genomes of zebrafish, Gasterosteus aculeatus, Oryzias latipes and Takifugu rubripes (Figure 11). This hypothetical protein, which we name here ECMZ, has a predicted sequence that appears to be related to the SLRP1 sequences from both Ciona species (Figures

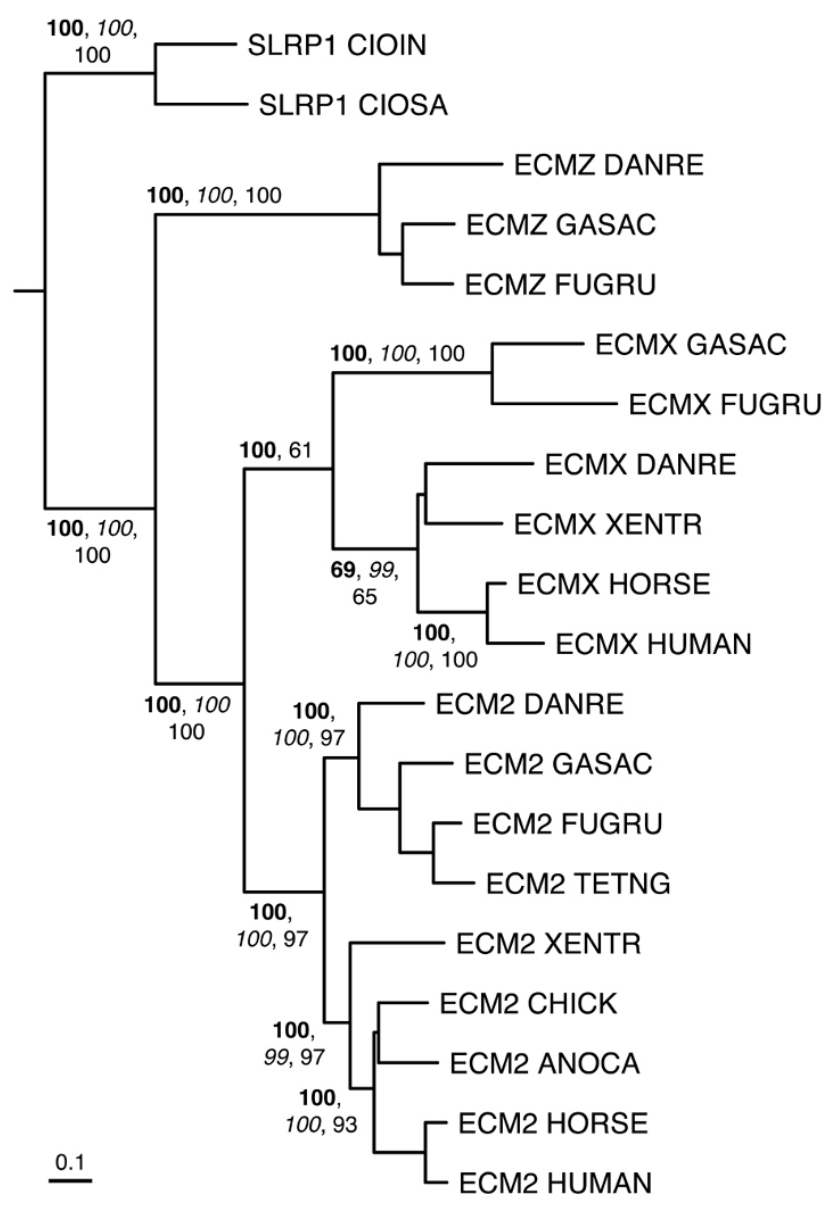

Figure 10

Phylogenetic relationships of class A SLRPs (ECM2 and ECM2-like sequences), inferred from the multiple sequence alignment of LRR domains from a reduced set of SLRP sequences (see Methods). The tree has been rooted using the SLRPI sequences from the two Ciona species as outgroup. Sequences group into three main clusters: ECM2, ECMX (ECM2-like protein from the $X$ chromosome), and ECMZ (ECM2-like predicted protein upstream of the DCN gene in fish genomes). Clade probability values higher than $60 \%$ are indicated as in Figure 6 . The scale bar represents amino acid substitutions per site.

4 and 10). These ECMZ sequences would therefore be the most similar to the ancient SLRP genes (or what is left of them) in vertebrates, and have not been retained in mammals, birds or reptiles. Given the number of ECM2-like sequences and their own clustering with the SLRP1 Ciona genes, away from classes I, II and III (Figure 4), we propose a new SLRP class that includes ECM2, ECMX, ECMZ and the Ciona SLRP1 sequences. Since these sequences appear to be more closely related to the ancestral gene from which all the canonical SLRPs derived, we name this new class "class A", for ancestral SLRPs. The similarity 


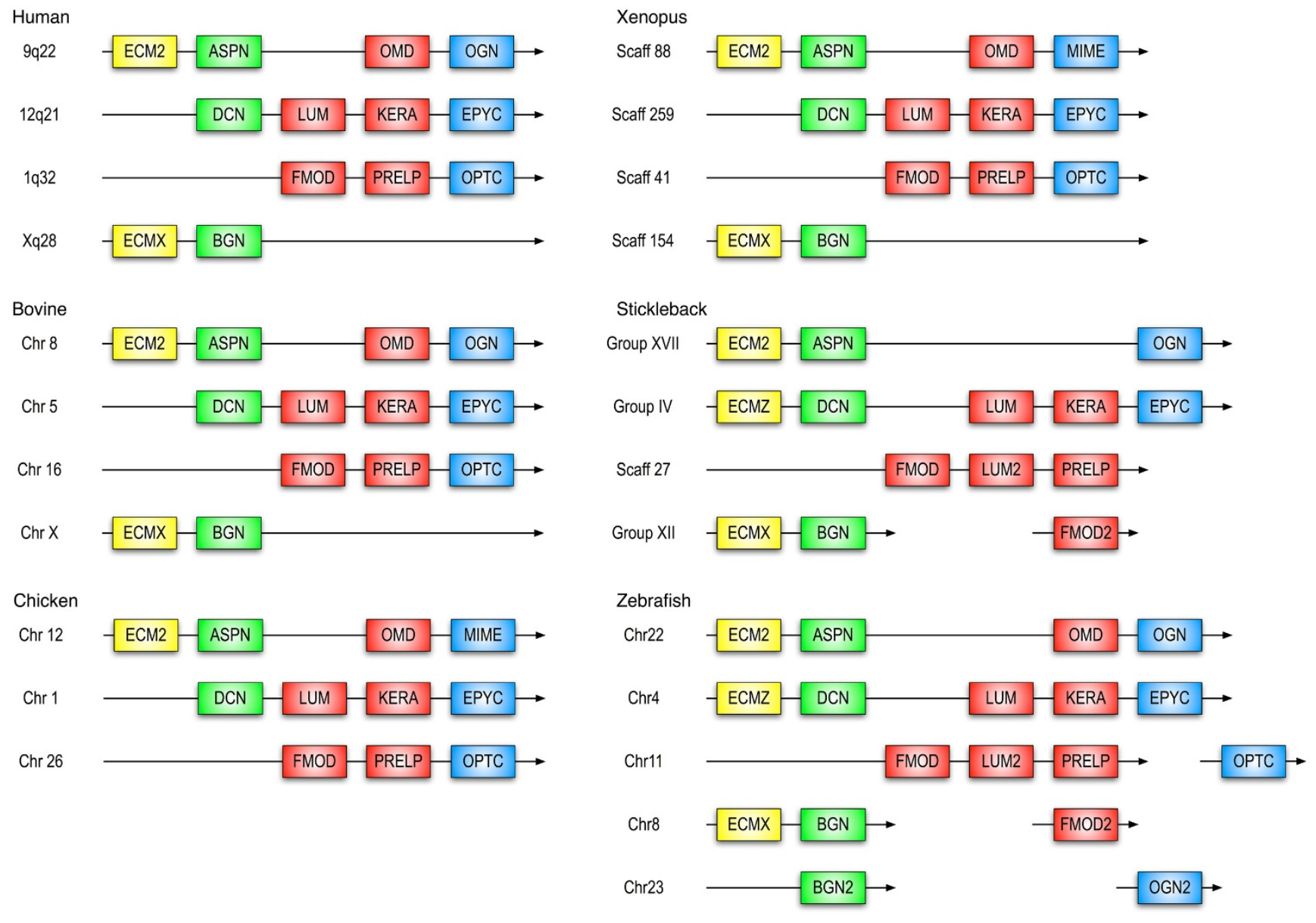

Figure II

Synteny of the genes from canonical SLRPs in several vertebrate genomes. Chromosomal or group location is shown when available in the ENSEMBL database, otherwise scaffold information is provided. Members from the four classes are shown in different colours: yellow (class A), green (class I), red (class II) and blue (class III). Genes shown consecutively do not have any other currently known genes in between, whereas the OPTC, FMOD2 and OGN2 genes in zebrafish and stickleback are separated from the other SLRPs by non-SLRP genes.

between the ECM2-ASPN gene tandem and the predicted ECMX-BGN and ECMZ-DCN tandems (Figure 11) strongly supports the notion of SLRP evolution by tandem and large-scale gene duplications as well as tandem gene migration $[57,64]$. The duplicate copies of SLRP genes exclusive to ray-finned fishes (LUM2, FMOD2, OGN2, BGN2) appear in the same chromosomes as other SLRP sequences (Figure 11). These duplicates may be survivors of the proposed, fish-specific large-scale gene or genome duplication that would have occurred after the divergence between the actinopterygian (ray-finned fishes) and sarcopterygian (coelacanth, lungfish and all land vertebrates) lineages [65-68]. Not all the zebrafish SLRP genes shown in Figure 11 have been identified in the other fish genomes, reflecting the fact that different teleost fishes have retained different sets of duplicate genes $[69,70]$. Comparison of the zebrafish and fugu genomes have revealed that despite a high degree of synteny and retention of a similar number of duplicates, in a significant number of cases, different paralogues have been preserved [70].

Finally, the chromosomal organization of the canonical SLRP genes in mammals follows the order shown in Figure 11 for the human and bovine genomes, where the class A paralogue is followed downstream by those from classes I, IIa, IIb and III. This organization would suggest that the ECMX-BGN pair might have been initially part of the FMOD-PRELP-OPTC gene cluster that currently is located in the chromosome 1 in humans, and later migrated to the $\mathrm{X}$ chromosome (as postulated for the BGN gene in [64]). A hypothetical class IIa gene downstream of ASPN would have disappeared completely, potentially by pseudogenisation. The fish SLRP genes share in part this 
Table 3: Two representative examples of ECMX predicted sequences (accession codes in parentheses).

\begin{tabular}{|c|c|c|c|c|}
\hline LRR & ECMX_DANRE (QILYN3_DANRE) & $\mathbf{N}$ & ECMX_HORSE (XP_00I49I563) & $\mathbf{N}$ \\
\hline & ...HMESLPSGCLLS & & ...AVPSLPASCLLA & \\
\hline I & ESLIACGNTRLTQMPIIRDAG & 21 & RAAIACGNVKMKHVPALTDPG & 21 \\
\hline ॥ & VRSLFLADNKISKIPAHALAGLPN & 24 & LTTLYLAENEIAKIPAHTFLGLPN & 24 \\
\hline III & LEWLDLSKNKLDDFSLAPDVFKNLTK & 26 & LEWLDLSKNKLDAQGLHPHAFKNLTR & 26 \\
\hline IV & LRRLNLDGNNFTKVPSLPPS & 20 & LKRLNLDGNSLSTVPALPTS & 20 \\
\hline$\vee$ & LVELKINDNKLSGLTPHSFKGLAQ & 24 & LQELKLNDNLLQGLQHSSFQGLSQ & 24 \\
\hline VI & LLTLELEDNYFHDGNVSPLAFKPLRQ & 26 & LLTLEVEGNQLHDGNISPLAFQPLRS & 26 \\
\hline VII & LIYLRLDDNKFRAIPSGLPVS & 21 & LVYLRLDRNQLRTIPPGLPAS & 21 \\
\hline VIII & VQELHLSDNKIEVVHSGLLNKTTN & 24 & LQELHLSTNAIEEVSEGALNRSRN & 24 \\
\hline IX & LRVLNLSHNRLREDRIHPRAWIHLLK & 26 & LRVLVLSNNQLQEDRLAPRAWIDLPK & 26 \\
\hline$x$ & LEFLDLSHNKLVHVPSFLPVG & 21 & LETLDLSHNRLVHVPSFLPRG & 21 \\
\hline $\mathrm{XI}$ & LRQLVLHHNQIERIPGYVFGHLRPG & 25 & LRHLTLHHNRIERIPGYVFAHMKPG & 25 \\
\hline XII & LDSLQLSYNRLREDGINEVSFIGLYNS & 27 & LEFLHLSHNSLGADGIHSVSFLGLHAS & 27 \\
\hline XIII & LTELLLDHNQLRAIPRGIVQLKS & 23 & LAELLLDHNQLQAIPRGLLGLRR & 23 \\
\hline XIV & LQHLRLNHNYISYVTMNSLCDTTARDDSS & 29 & LQVLRLSHNKIRYVPLNSICDTRVAQDSN & 29 \\
\hline \multirow[t]{2}{*}{$X V$} & LVSVHLEFNLIERRLIPPTAFSCIRTY & 27 & LISTHLENNLIDRRRIPPTAFSCIRAY & 27 \\
\hline & .QSVLLRPQRYEEHQI & & .HSVVLQPQQGEGEGS & \\
\hline
\end{tabular}

Repeats are numbered in roman numerals, and $N$ is the length of each repeat. Sequences amino terminal to the LRRNT cluster have not been included.

chromosomal organization (Figure 11), and the class A SLRP upstream of the DCN gene can still be recognized in the predicted ECMZ sequences. An exception is presented by the LUM2 (class IIa) sequence in fishes, which appears intercalated between the FMOD (IIa) and PRELP (IIb) genes but is missing in non-fish genomes. The LUM2 sequence could have originated from additional local gene duplication in fishes or could have migrated from a different SLRP gene cluster. The presence of the additional fish SLRP duplicates (BGN2, FMOD2 and OGN2) points towards a complex history of local and large-scale duplications as well as gene migration for the surviving set of fish SLRPs.

\section{Possible biological roles for LRRCE motifs}

Probably the main role of the LRRCE motifs is to stabilize the LRR structures of the SLRPs by providing a disulphidebonded C-terminal capping structure, in a similar manner to the LRRCT capping motifs present in many sequences of extracellular or membrane-associated LRR proteins. The requirement of disulphide-bonding integrity for SLRP biological actitvity has been demonstrated for decorin [71] and fibromodulin [72]. Furthermore, thermal denaturation of decorin appears to be completely reversible as long as the disulphide bonds are not reduced [31].

Several diseased states have been associated to mutations occurring in the LRRCE regions of some SLRPs. Two different frame shift mutations on the decorin gene due to single base pair deletions in the LRRCE coding region have been linked to congenital stromal dystrophy of the cornea $[73,74]$. Both mutations are predicted to result in a truncated decorin protein missing the last $33 \mathrm{C}$-terminal amino acids. Another mutation resulting in a premature stop codon in the ear extension of keratocan (R313X) has been linked to autosomal recessive cornea plana $[75,76]$. These two truncations would eliminate most of the LRRCE structure in decorin and keratocan. Three amino acid substitutions in the LRRCE motif of opticin have been linked to high myopia [77], probably through disruption of the local tertiary structure. In all these examples, the predicted truncation or alteration of the LRRCE structure is likely to have a detrimental effect in the stability of the entire LRR domains of these SLRPs.

A direct role of the ear extensions in ligand binding remains an attractive yet still hypothetical scenario. The expanded set of LRRCE sequences presented here shows clear conservation trends across species in the ear extensions of a given SLRP, whereas these extensions are poorly conserved between closely related SLRPs. Thus, the ear extensions could help to differentiate the roles of SLRPs belonging to the same class. In known structures of LRR domains or proteins it is not uncommon to find extended repeats where the polypeptide chain loops out from the expected path of a regular LRR to rejoin it some residues later [5]. These extensions may have functional significance, as shown for example by the so-called $\beta$-switch and $\beta$-finger in the structure of glycoprotein $\operatorname{Ib} \alpha[44,45]$. Future biochemical and mutagenesis analyses on the SLRP ear extensions will be necessary to elucidate any functional role of these structures in ligand recognition and binding. 


\section{Conclusion}

The LRRCE capping motif identified in the structures of the representative SLRPs decorin and biglycan appears to be a structural element exclusive to the main group of SLRPs, which includes the previously described classes I, II and III, plus a new class of ancestral genes that includes ECM2, the SLRP1 sequences from Ciona, and other ECM2like sequences present mainly in fishes but with intriguing orthologues in mammals, including a yet uncharacterized new SLRP in the human X chromosome. The LRRCE motif appears to have evolved during early chordate evolution and is not found in non-chordate LRR protein sequences. Such evolutionary history is probably related to the known interactions of SLRPs with fibrilllar collagens and their regulation of collagen fibrillogenesis [10,33,34]. Given its exclusivity to the SLRP family, the LRRCE motif is a useful annotation tool for the identification and classification of new SLRP sequences in genome sequencing efforts. Analysis of LRRCE-containing sequences of organisms located phylogenetically between critical evolutionary events will provide useful clues for understanding the history of large-scale gene and genome duplications that appear to have occurred during vertebrate evolution. The expanded list of SLRP sequences, provided here for the first time, will facilitate the analysis of residue conservation trends in functionally significant sequence motifs, and ultimately will be useful for the elucidation of the full range of biological functions of this important family of extracellular matrix molecules.

\section{Methods}

\section{Regular expression pattern and sequence retrieval}

An initial set of 58 protein sequences annotated as SLRPs from classes I (21 sequences), II (24 sequences) and III (12 sequences) plus ECM2 (1 sequence) were selected from the Swiss-Prot database (52.1 release, http:// www.ebi.ac.uk/swissprot) and aligned using CINEMA [78]. This alignment was used together with the crystal structures of decorin and biglycan (PDB codes $\underline{1 X K U}$ and $\underline{2 F T 3}$ respectively), to define a characteristic regular expression pattern using PROSITE syntax [79]. This pattern, designated as LRRCE hereupon, was used to retrieve additional sequences from the UniProt database (SwissProt release 55.1, TrEMBL release 38.1) [48] using the ScanProsite tool [80]. The LRRCE regular expression pattern was refined in iterative cycles until no further sequences were obtained. The final LRRCE expression pattern, in PROSITE syntax [79], was: [LIV]-X(2)-[LVIYFMA]X-[LIFM]-X(2)-[NH]-X-[ILVF]-X(2)-[VIMFLY]-X(4)[FIMLV]-C-X(7,20)-[LYIMV]-X(2)-[ILVTMF]-X-[LVMI]X(2)-N-X-[IVLMAFT]-X(8,9)-[FYMPVAIS]-X-C.

\section{Similarity searches and sequence alignment}

Additional sequences were obtained through sequence similarity searches (BLAST and TBLASTN) on the NCBI
[81] and ENSEMBL [82] databases. Sequences of LRRCE motifs from different organisms were used to query the different databases. Given the early stages of annotation of some of the genomes, some predicted sequences were manually corrected using supporting genome and EST data. The sequences were aligned using CLUSTALW [83] as implemented in the Kyoto University Bioinformatics Center http://align.genome.jp.

\section{Phylogenetic analyses}

The phylogenetic analysis shown in Figure 4 was inferred from a multiple sequence alignment of the LRRCE motifs of the 280 sequences retrieved by ScanProsite and the similarity searches described above. The complete list of sequences used in this study and their accession numbers are provided in Additional File 1. Separate phylogenetic analyses were performed for each SLRP class on a reduced set of sequences from two mammals (human and bovine or horse), two birds (chicken and quail), lizard (anole), frog (Xenopus), four teleost fishes (zebrafish, stickleback, fugu and Tetraodon), lamprey, and the two Ciona species (Figures 6, 7, 8, 9, 10). For each class, phylogenetic analyses were inferred from a gap stripped multiple alignment of the selected sequences generated using CLUSTALW [83] and analyzed by three different independent phylogenetic methods. Neighbour-joining (NJ) trees and bootstrap replicates were generated using SEQBOOT, PROTDIST, NEIGHBOR and CONSENSE from the PHYLIP package [84] using default settings. Maximum Likelihood trees were inferred using PROML from the PHYLIP package using default settings. Bayesian tree inference values were produced using the MrBayes programme [85], where Markov Chain Monte Carlo analysis was performed for 100,000 generations using 6 chains. Cladecredibility values indicating statistically probable clades ( $>60 \%$ ) are indicated from the three methods on the NJ trees (Figures 6, 7, 8, 9, 10), and UniProt organism abbreviations are used for sequence identification: XENTR, Xenopus tropicalis (western clawed frog); ANOCA, Anolis carolinensis (anole lizard); CHICK, Gallus gallus (chicken); COTJA, Coturnix japonica (Japanese quail); DANRE, Danio rerio (zebrafish); GASAC, Gasterosteus aculeatus (stickleback); TETNG, Tetraodon nigroviridis (green pufferfish); FUGRU, Fugu rubripes (Japanese pufferfish); PETMA, Petromyzon marinus (sea lamprey); CIOIN, Ciona intestinalis (transparent sea squirt); CIOSA, Ciona savignyi (Pacific transparent sea squirt).

\section{Molecular diagrams}

The ribbon diagrams and molecular representations from Figures 1 and 2 were produced using the program SETOR [86]. 


\section{Authors' contributions}

$\mathrm{HP}$ is responsible for creating the sequence patterns, data collection and phylogenetic analysis. JHJ contributed to the production and analysis of phylogenetic trees and to the evolutionary and biological insights of the manuscript. RPBH and PNB contributed to the evolutionary and biological insights of the manuscript. TKA contributed to the data analysis and helped in the supervision of the bioinformatic analysis. JB conceived the study, analyzed the data and wrote the manuscript. All authors read and approved the final manuscript.

\section{Additional material}

\section{Additional file 1}

LRRCE sequences and accession codes. Expanded set of LRRCE sequences including accession codes to sequence databases.

Click here for file

[http://www.biomedcentral.com/content/supplementary/1471-

2164-9-599-S1.pdf]

\section{Additional file 2}

high-resolution version of Figure 4. Larger version of Figure 4, with legible sequence names at the end of the phylogenetic tree branches.

Click here for file

[http://www.biomedcentral.com/content/supplementary/14712164-9-599-S2.tiff]

\section{Acknowledgements}

HP acknowledges a Chevening Scholarship, funded by the Foreign and Commonwealth Office of the British Government, to support her postgraduate studies. JHJ acknowledges funding by a BBSRC PhD studentship. RBH, PNB and JB are members of the Wellcome Trust Centre for CellMatrix Research, supported by the Wellcome Trust.

\section{References}

I. Kobe B, Deisenhofer J: Proteins with leucine-rich repeats. Curr Opin Struct Biol 1995, 5(3):409-4I6.

2. Kajava AV: Structural diversity of leucine-rich repeat proteins. J Mol Biol 1998, 277(3):519-527.

3. Kobe $B$, Kajava AV: The leucine-rich repeat as a protein recognition motif. Curr Opin Struct Biol 200I, I I (6):725-732.

4. Enkhbayar P, Kamiya M, Osaki M, Matsumoto T, Matsushima N Structural principles of leucine-rich repeat (LRR) proteins. Proteins 2004, 54(3):394-403.

5. Bella J, Hindle KL, McEwan PA, Lovell SC: The leucine-rich repeat structure. Cell Mol Life Sci 2008, 65( I 5):2307-2333.

6. Buchanan SG, Gay NJ: Structural and functional diversity in the leucine-rich repeat family of proteins. Prog Biophys $\mathrm{Mol} \mathrm{Biol}$ 1996, 65(I-2): |-44.

7. Kobe $B$, Deisenhofer J: The leucine-rich repeat: a versatile binding motif. Trends Biochem Sci 1994, I 9(10):415-42I.

8. Kobe $B$, Deisenhofer J: A structural basis of the interactions between leucine-rich repeats and protein ligands. Nature 1995, 374(65 18): 183-186.

9. Kajava AV, Vassart G, Wodak SJ: Modeling of the three-dimensional structure of proteins with the typical leucine-rich repeats. Structure 1995, 3(9):867-877.

10. Hocking AM, Shinomura T, McQuillan DJ: Leucine-rich repeat glycoproteins of the extracellular matrix. Matrix Biol 1998, I7(I): I-19.
II. Kresse H, Schönherr E: Proteoglycans of the extracellular matrix and growth control. J Cell Physiol 200I, I 89(3):266-274

12. Martinon F, Tschopp J: NLRs join TLRs as innate sensors of pathogens. Trends Immunol 2005, 26(8):447-454.

13. Matilla A, Radrizzani M: The Anp32 family of proteins containing leucine-rich repeats. Cerebellum 2005, 4(I):7-I8

14. Chen Y, Aulia S, Li L, Tang BL: AMIGO and friends: an emerging family of brain-enriched, neuronal growth modulating, type I transmembrane proteins with leucine-rich repeats (LRR) and cell adhesion molecule motifs. Brain Res Rev 2006, 5 I (2):265-274.

15. Hohenester E, Hussain S, Howitt JA: Interaction of the guidance molecule Slit with cellular receptors. Biochem Soc Trans 2006, 34(Pt 3):4|8-42|.

16. McHale L, Tan X, Koehl P, Michelmore RW: Plant NBS-LRR proteins: adaptable guards. Genome Biol 2006, 7(4):2 I 2.

17. Pancer Z, Cooper MD: The evolution of adaptive immunity. Annu Rev Immunol 2006, 24:497-5I 8.

18. Bierne H, Sabet C, Personnic N, Cossart P: Internalins: a complex family of leucine-rich repeat-containing proteins in Listeria monocytogenes. Microbes Infect 2007, 9(I 0): I I 56-I I 66.

19. Gay NJ, Gangloff M: Structure and function of Toll receptors and their ligands. Annu Rev Biochem 2007, 76:141-165.

20. Vanhoorelbeke K, Ulrichts H, Walle G Van de, Fontayne A, Deckmyn $\mathrm{H}$ : Inhibition of platelet glycoprotein Ib and its antithrombotic potential. Curr Pharm Des 2007, I3(26):2684-2697.

21. Kobe B, Deisenhofer J: Crystal structure of porcine ribonuclease inhibitor, a protein with leucine-rich repeats. Nature 1993 , 366(6457):75I-756.

22. Price SR, Evans PR, Nagai K: Crystal structure of the spliceosomal U2B"-U2A' protein complex bound to a fragment of U2 small nuclear RNA. Nature 1998, 394(6694):645-650.

23. Kim JI, Lee CJ, Jin MS, Lee CH, Paik SG, Lee H, Lee JO: Crystal structure of CD I 4 and its implications for lipopolysaccharide signaling. J Biol Chem 2005, 280( I 2): | | 347- I | 35 |

24. Bell JK, Askins J, Hall PR, Davies DR, Segal DM: The dsRNA binding site of human Toll-like receptor 3. Proc Natl Acad Sci USA 2006, I 03(23):8792-8797.

25. Jin MS, Kim SE, Heo JY, Lee ME, Kim HM, Paik SG, Lee H, Lee JO: Crystal structure of the TLRI-TLR2 heterodimer induced by binding of a tri-acylated lipopeptide. Cell 2007, I 30(6): $107 \mid-1082$

26. Kim HM, Park BS, Kim JI, Kim SE, Lee J, Oh SC, Enkhbayar P, Matsushima N, Lee H, Yoo OJ, Lee JO: Crystal structure of the TLR4MD-2 complex with bound endotoxin antagonist Eritoran. Cell 2007, I30(5):906-917.

27. Tan X, Calderon-Villalobos LI, Sharon M, Zheng C, Robinson CV, Estelle $M$, Zheng $N$ : Mechanism of auxin perception by the TIRI ubiquitin ligase. Nature 2007, 446(7 I 36):640-645.

28. Scott PG, Grossmann JG, Dodd CM, Sheehan JK, Bishop PN: Light and $X$-ray scattering show decorin to be a dimer in solution. J Biol Chem 2003, 278(20): I8353-I8359.

29. Scott PG, McEwan PA, Dodd CM, Bergmann EM, Bishop PN, Bella J: Crystal structure of the dimeric protein core of decorin, the archetypal small leucine-rich repeat proteoglycan. Proc Nat Acad Sci USA 2004, I 01 (44): I5633-15638.

30. Howitt JA, Clout NJ, Hohenester E: Binding site for Robo receptors revealed by dissection of the leucine-rich repeat region of Slit. EMBO J 2004, 23(22):4406-44I 2.

31. Scott PG, Dodd CM, Bergmann EM, Sheehan JK, Bishop PN: Crystal structure of the biglycan dimer and evidence that dimerization is essential for folding and stability of class I small leucine-rich repeat proteoglycans. J Biol Chem 2006, 28 I ( I 9): | 3324-I3332.

32. McEwan PA, Scott PG, Bishop PN, Bella J: Structural correlations in the family of small leucine-rich repeat proteins and proteoglycans. J Struct Biol 2006, I 55(2):294-305.

33. Ameye L, Young MF: Mice deficient in small leucine-rich proteoglycans: novel in vivo models for osteoporosis, osteoarthritis, Ehlers-Danlos syndrome, muscular dystrophy, and corneal diseases. Glycobiology 2002, I 2(9): I07R-I I6R.

34. Schaefer L, lozzo RV: Biological functions of the small leucinerich proteoglycans: from genetics to signal transduction. J Biol Chem 2008, 283(3 I):2 I 305-21 309. 
35. Waddington RJ, Roberts HC, Sugars RV, Schönherr E: Differential roles for small leucine-rich proteoglycans in bone formation. Eur Cell Mater 2003, 6: I2-2I.

36. Ross MD, Bruggeman LA, Hanss B, Sunamoto M, Marras D, Klotman ME, Klotman PE: Podocan, a novel small leucine-rich repeat protein expressed in the sclerotic glomerular lesion of experimental HIV-associated nephropathy. J Biol Chem 2003, 278(35):33248-33255.

37. Ohta K, Lupo G, Kuriyama S, Keynes R, Holt CE, Harris WA, Tanaka $H$, Ohnuma S: Tsukushi functions as an organizer inducer by inhibition of BMP activity in cooperation with chordin. Dev Cell 2004, 7(3):347-358.

38. O'Connor E, Eisenhaber B, Dalley J, Wang T, Missen C, Bulleid N, Bishop PN, Trump D: Species specific membrane anchoring of nyctalopin, a small leucine-rich repeat protein. Hum Mol Genet 2005, I 4(13): | 877-1887.

39. Mochida Y, Parisuthiman D, Kaku M, Hanai J, Sukhatme VP, Yamauchi $M$ : Nephrocan, a novel member of the small leucine-rich repeat protein family, is an inhibitor of transforming growth factor- $\beta$ signaling. J Biol Chem 2006, 28 I(47):36044-3605I.

40. Letunic I, Copley RR, Pils B, Pinkert S, Schultz J, Bork P: SMART 5: domains in the context of genomes and networks. Nucleic Acids Res 2006:D257-D260.

4I. Finn RD, Mistry J, Schuster-Böckler B, Griffiths-Jones S, Hollich V, Lassmann T, Moxon S, Marshall M, Khanna A, Durbin R, Eddy SR, Sonnhammer EL, Bateman A: Pfam: clans, web tools and services. Nucleic Acids Res 2006:D247-D25I.

42. Mulder NJ, Apweiler R, Attwood TK, Bairoch A, Bateman A, Binns D, Bork P, Buillard V, Cerutti L, Copley R, Courcelle E, Das U, Daugherty L, Dibley M, Finn R, Fleischmann W, Gough J, Haft D, Hulo N, Hunter S, Kahn D, Kanapin A, Kejariwal A, Labarga A, LangendijkGenevaux PS, Lonsdale D, Lopez R, Letunic I, Madera M, Maslen J, McAnulla C, McDowall J, Mistry J, Mitchell A, Nikolskaya AN, Orchard S, Orengo C, Petryszak R, Selengut JD, Sigrist C], Thomas PD, Valentin F, Wilson D, Wu CH, Yeats C: New developments in the InterPro database. Nucleic Acids Res 2007:D224-D228.

43. Di Matteo A, Federici L, Mattei B, Salvi G, Johnson KA, Savino C, De Lorenzo G, Tsernoglou D, Cervone F: The crystal structure of polygalacturonase-inhibiting protein (PGIP), a leucine-rich repeat protein involved in plant defense. Proc Natl Acad Sci USA 2003, I00(17): 10124-10128.

44. Huizinga EG, Tsuji S, Romijn RA, Schiphorst ME, de Groot PG, Sixma JJ, Gros P: Structures of glycoprotein Iba and its complex with von Willebrand factor AI domain. Science 2002, 297(5584): I |76-I I79.

45. Uff S, Clemetson JM, Harrison T, Clemetson KJ, Emsley J: Crystal structure of the platelet glycoprotein Iba $\mathbf{N}$-terminal domain reveals an unmasking mechanism for receptor activation. J Biol Chem 2002, 277(38):35657-35663.

46. He XL, Bazan JF, McDermott G, Park JB, Wang K, Tessier-Lavigne M, $\mathrm{He} Z$, Garcia KC: Structure of the Nogo receptor ectodomain: a recognition module implicated in myelin inhibition. Neuron 2003, 38(2): | 77-185.

47. Barton WA, Liu BP, Tzvetkova D, Jeffrey PD, Fournier AE, Sah D, Cate R, Strittmatter SM, Nikolov DB: Structure and axon outgrowth inhibitor binding of the Nogo-66 receptor and related proteins. EMBO J 2003, 22(I3):329I-3302.

48. UniProt Consortium: The universal protein resource (UniProt). Nucleic Acids Res 2008:D190-DI95.

49. Bell JK, Botos I, Hall PR, Askins J, Shiloach J, Segal DM, Davies DR: The molecular structure of the Toll-like receptor 3 ligandbinding domain. Proc Natl Acad Sci USA 2005, I 02(3 I): I0976-10980.

50. Choe J, Kelker MS, Wilson IA: Crystal structure of human tolllike receptor 3 (TLR3) ectodomain. Science 2005, 309(5734):581-585

51. Honeybee Genome Sequence Consortium: Insights into social insects from the genome of the honeybee Apis mellifera. Nature 2006, 443(7 I I 4):93I-949.

52. Nene V, Wortman JR, Lawson D, Haas B, Kodira C, Tu ZJ, Loftus B, Xi Z, Megy K, Grabherr M, Ren Q, Zdobnov EM, Lobo NF, Campbell KS, Brown SE, Bonaldo MF, Zhu J, Sinkins SP, Hogenkamp DG Amedeo P, Arensburger P, Atkinson PW, Bidwell S, Biedler J, Birney E, Bruggner RV, Costas J, Coy MR, Crabtree J, Crawford M, Debruyn B, Decaprio D, Eiglmeier K, Eisenstadt E, El-Dorry H, Gelbart WM, Gomes SL, Hammond M, Hannick LI, Hogan JR, Holmes MH, Jaffe D,
Johnston JS, Kennedy RC, Koo H, Kravitz S, Kriventseva EV, Kulp D, Labutti K, Lee E, Li S, Lovin DD, Mao C, Mauceli E, Menck CF, Miller JR, Montgomery P, Mori A, Nascimento AL, Naveira HF, Nusbaum C, O'leary S, Orvis J, Pertea M, Quesneville H, Reidenbach KR, Rogers YH, Roth CW, Schneider JR, Schatz M, Shumway M, Stanke M, Stinson EO, Tubio JM, Vanzee JP, Verjovski-Almeida S, Werner D, White O, Wyder S, Zeng Q, Zhao Q, Zhao Y, Hill CA, Raikhel AS, Soares MB, Knudson DL, Lee NH, Galagan J, Salzberg SL, Paulsen IT, Dimopoulos G, Collins FH, Birren B, Fraser-Liggett CM, Severson DW: Genome sequence of Aedes aegypti, a major arbovirus vector. Science 2007, 3 | 6(5832): | 718-|723.

53. Sea Urchin Genome Sequencing Consortium: The genome of the sea urchin Strongylocentrotus purpuratus. Science 2006, 3 | 4(580 I): 94 I-952.

54. Putnam NH, Butts T, Ferrier DE, Furlong RF, Hellsten U, Kawashima T, Robinson-Rechavi M, Shoguchi E, Terry A, Yu JK, Benito-Gutiérrez EL, Dubchak I, Garcia-Fernàndez J, Gibson-Brown J], Grigoriev IV, Horton AC, de Jong PJ, Jurka J, Kapitonov VV, Kohara Y, Kuroki Y, Lindquist E, Lucas S, Osoegawa K, Pennacchio LA, Salamov AA, Satou Y, Sauka-Spengler T, Schmutz J, Shin-I T, Toyoda A, Bronner-Fraser M, Fujiyama A, Holland LZ, Holland PW, Satoh N, Rokhsar DS: The amphioxus genome and the evolution of the chordate karyotype. Nature 2008, 453(7| 98): I064-107|.

55. Dehal P, Satou Y, Campbell RK, Chapman J, Degnan B, De Tomaso A, Davidson B, Di Gregorio A, Gelpke M, Goodstein DM, Harafuji N, Hastings KE, Ho I, Hotta K, Huang W, Kawashima T, Lemaire P, Martinez D, Meinertzhagen IA, Necula S, Nonaka M, Putnam N, Rash S, Saiga H, Satake M, Terry A, Yamada L, Wang HG, Awazu S, Azumi K, Boore J, Branno M, Chin-Bow S, DeSantis R, Doyle S, Francino P, Keys DN, Haga S, Hayashi H, Hino K, Imai KS, Inaba K, Kano S, Kobayashi K, Kobayashi M, Lee BI, Makabe KW, Manohar C, Matassi G, Medina M, Mochizuki Y, Mount S, Morishita T, Miura S, Nakayama A Nishizaka S, Nomoto H, Ohta F, Oishi K, Rigoutsos I, Sano M, Sasaki A, Sasakura Y, Shoguchi E, Shin-i T, Spagnuolo A, Stainier D, Suzuki MM, Tassy O, Takatori N, Tokuoka M, Yagi K, Yoshizaki F, Wada S, Zhang C, Hyatt PD, Larimer F, Detter C, Doggett N, Glavina T, Hawkins T, Richardson P, Lucas S, Kohara Y, Levine M, Satoh N, Rokhsar DS: The draft genome of Ciona intestinalis: insights into chordate and vertebrate origins. Science 2002 , 298(560I):2I57-2I67.

56. Small KS, Brudno M, Hill MM, Sidow A: A haplome alignment and reference sequence of the highly polymorphic Ciona savignyi genome. Genome Biol 2007, 8(3):R4I.

57. Huxley-Jones J, Robertson DL, Boot-Handford RP: On the origins of the extracellular matrix in vertebrates. Matrix Biol 2007, 26(I):2-II.

58. Matsushima N, Ohyanagi T, Tanaka T, Kretsinger RH: Super-motifs and evolution of tandem leucine-rich repeats within the small proteoglycans - biglycan, decorin, lumican, fibromodulin, PRELP, keratocan, osteoadherin, epiphycan, and osteoglycin. Proteins 2000, 38(2):210-225.

59. Delsuc F, Brinkmann H, Chourrout D, Philippe $H$ : Tunicates and not cephalochordates are the closest living relatives of vertebrates. Nature 2006, 439(7079):965-968.

60. Shintani S, Sato A, Toyosawa S, O'hUigin C, Klein J: Biglycan-like extracellular matrix genes of agnathans and teleosts. J Mol Evol 2000, 5 I (4):363-373.

6I. Escriva H, Manzon L, Youson J, Laudet V: Analysis of lamprey and hagfish genes reveals a complex history of gene duplications during early vertebrate evolution. Mol Biol Evol 2002, I 9(9): | 440-| 450.

62. Kuratani S, Kuraku S, Murakami Y: Lamprey as an evo-devo model: lessons from comparative embryology and molecular phylogenetics. Genesis 2002, 34(3): I75-। 83.

63. Blaschke UK, Hedbom E, Bruckner P: Distinct isoforms of chicken decorin contain either one or two dermatan sulfate chains. Biol Chem 1996, 27 I (48):30347-30353.

64. Henry SP, Takanosu M, Boyd TC, Mayne PM, Eberspaecher H, Zhou W, de Crombrugghe B, Hook M, Mayne R: Expression pattern and gene characterization of asporin. a newly discovered member of the leucine-rich repeat protein family. J Biol Chem 200I, 276(I5): |22|2-|222|.

65. Jaillon O, Aury JM, Brunet F, Petit JL, Stange-Thomann N, Mauceli E, Bouneau L, Fischer C, Ozouf-Costaz C, Bernot A, Nicaud S, Jaffe D, Fisher S, Lutfalla G, Dossat C, Segurens B, Dasilva C, Salanoubat M, Levy M, Boudet N, Castellano S, Anthouard V, Jubin C, Castelli V, 
Katinka M, Vacherie B, Biémont C, Skalli Z, Cattolico L, Poulain J, De Berardinis V, Cruaud C, Duprat S, Brottier P, Coutanceau JP, Gouzy J, Parra G, Lardier G, Chapple C, McKernan KJ, McEwan P, Bosak S, Kellis M, Volff JN, Guigó R, Zody MC, Mesirov J, Lindblad-Toh K, Birren B, Nusbaum C, Kahn D, Robinson-Rechavi M, Laudet V, Schachter V, Quétier F, Saurin W, Scarpelli C, Wincker P, Lander ES, Weissenbach J, Roest Crollius H: Genome duplication in the teleost fish Tetraodon nigroviridis reveals the early vertebrate protokaryotype. Nature 2004, 43 I (70 I I):946-957.

66. Christoffels A, Koh EG, Chia JM, Brenner S, Aparicio S, Venkatesh B: Fugu genome analysis provides evidence for a wholegenome duplication early during the evolution of ray-finned fishes. Mol Biol Evol 2004, 2 I (6): I I 46-I I I I.

67. Peer $Y$ Van de: Tetraodon genome confirms Takifugu findings: most fish are ancient polyploids. Genome Biol 2004, 5(I 2):250.

68. Meyer A, Peer $Y$ Van de: From 2R to 3R: evidence for a fish-specific genome duplication (FSGD). Bioessays 2005, 27(9):937-945.

69. Taylor JS, Braasch I, Frickey T, Meyer A, Peer Y Van de: Genome duplication, a trait shared by 22000 species of ray-finned fish. Genome Res 2003, I3(3):382-390.

70. Woods IG, Wilson C, Friedlander B, Chang P, Reyes DK, Nix R, Kelly PD, Chu F, Postlethwait JH, Talbot WS: The zebrafish gene map defines ancestral vertebrate chromosomes. Genome Res 2005, I5(9): $1307-|3| 4$.

7I. Scott PG, Winterbottom N, Dodd CM, Edwards E, Pearson CH: A role for disulphide bridges in the protein core in the interaction of proteodermatan sulphate and collagen. Biochem Biophys Res Commun 1986, 138(3):1348-1354.

72. Scott PG, Nakano T, Dodd CM: Isolation and characterization of small proteoglycans from different zones of the porcine knee meniscus. Biochim Biophys Acta 1997, I 336(2):254-262.

73. Bredrup C, Knappskog PM, Majewski J, Rødahl E, Boman H: Congenital stromal dystrophy of the cornea caused by a mutation in the decorin gene. Invest Ophthalmol Vis Sci 2005, 46(2):420-426.

74. Rødahl E, Van Ginderdeuren R, Knappskog PM, Bredrup C, Boman H: A second decorin frame shift mutation in a family with congenital stromal corneal dystrophy. Am J Ophthalmol 2006, I 42(3):520-52।.

75. Khan A, Al-Saif A, Kambouris M: A novel KERA mutation associated with autosomal recessive cornea plana. Ophthalmic Genet 2004, 25(2): 147-152.

76. Matsushima N, Tachi N, Kuroki Y, Enkhbayar P, Osaki M, Kamiya M, Kretsinger RH: Structural analysis of leucine-rich-repeat variants in proteins associated with human diseases. Cell Mol Life Sci 2005, 62(23):277I-279I.

77. Majava M, Bishop PN, Hägg P, Scott PG, Rice A, Inglehearn C, Hammond C], Spector TD, Ala-Kokko L, Männikkö M: Novel mutations in the small leucine-rich repeat protein/proteoglycan (SLRP) genes in high myopia. Hum Mutat 2007, 28(4):336-344.

78. Lord PW, Selley JN, Attwood TK: CINEMA-MX: a modular multiple alignment editor. Bioinformatics 2002, I8(10): | $402-1403$.

79. Sigrist CJ, Cerutti L, Hulo N, Gattiker A, Falquet L, Pagni M, Bairoch A, Bucher P: PROSITE: a documented database using patterns and profiles as motif descriptors. Brief Bioinform 2002, 3(3):265-274

80. de Castro E, Sigrist CJ, Gattiker A, Bulliard V, Langendijk-Genevaux PS, Gasteiger E, Bairoch A, Hulo N: ScanProsite: detection of PROSITE signature matches and ProRule-associated functional and structural residues in proteins. Nucleic Acids Res 2006:W362-W365.

81. Ye J, McGinnis S, Madden TL: BLAST: improvements for better sequence analysis. Nucleic Acids Res 2006:W6-W9.

82. Birney E, Andrews D, Caccamo M, Chen Y, Clarke L, Coates G, Cox T, Cunningham F, Curwen V, Cutts T, Down T, Durbin R, FernandezSuarez XM, Flicek P, Gräf S, Hammond M, Herrero J, Howe K, lyer V, Jekosch K, Kähäri A, Kasprzyk A, Keefe D, Kokocinski F, Kulesha E, London D, Longden I, Melsopp C, Meidl P, Overduin B, Parker A, Proctor G, Prlic A, Rae M, Rios D, Redmond S, Schuster M, Sealy I, Searle S, Severin J, Slater G, Smedley D, Smith J, Stabenau A, Stalker J, Trevanion S, Ureta-Vidal A, Vogel J, White S, Woodwark C, Hubbard TJ: Ensembl 2006. Nucleic Acids Res 2006:D556-D56I.

83. Thompson JD, Higgins DG, Gibson TJ: CLUSTAL W: improving the sensitivity of progressive multiple sequence alignment through sequence weighting, position-specific gap penalties and weight matrix choice. Nucleic Acids Res 1994, 22(22):4673-4680.

84. Felsenstein J: PHYLIP (Phylogeny Inference Package). In Version 3.6 Department of Genome Sciences, University of Washington, Seattle; 2006.

85. Huelsenbeck JP: MrBayes: Bayesian inference of phylogeny. Department of Biology, University of Rochester. Distributed by the author; 2000.

86. Evans SV: SETOR: hardware-lighted three-dimensional solid model representations of macromolecules. J Mol Graph 1993, I I(2): I34-I38.

87. Crooks GE, Hon G, Chandonia JM, Brenner SE: WebLogo: a sequence logo generator. Genome Res 2004, I 4(6): I I 88-I I 90.
Publish with Bio Med Central and every scientist can read your work free of charge

"BioMed Central will be the most significant development for disseminating the results of biomedical research in our lifetime. "

Sir Paul Nurse, Cancer Research UK

Your research papers will be:

- available free of charge to the entire biomedical community

- peer reviewed and published immediately upon acceptance

- cited in PubMed and archived on PubMed Central

- yours - you keep the copyright

Submit your manuscript here:

http://www.biomedcentral.com/info/publishing_adv.asp
BioMedcentral 